IZA DP No. 7286

Life Expectancy, Schooling, and Lifetime Labor Supply: Theory and Evidence Revisited

Matteo Cervellati

Uwe Sunde

March 2013

Forschungsinstitut zur Zukunft der Arbeit Institute for the Study of Labor 


\title{
Life Expectancy, Schooling, and Lifetime Labor Supply: Theory and Evidence Revisited
}

\author{
Matteo Cervellati \\ University of Bologna \\ and IZA \\ Uwe Sunde \\ University of Munich, \\ IZA and CEPR
}

\section{Discussion Paper No. 7286 \\ March 2013}

\author{
IZA \\ P.O. Box 7240 \\ 53072 Bonn \\ Germany \\ Phone: +49-228-3894-0 \\ Fax: +49-228-3894-180 \\ E-mail: iza@iza.org
}

\begin{abstract}
Any opinions expressed here are those of the author(s) and not those of IZA. Research published in this series may include views on policy, but the institute itself takes no institutional policy positions. The IZA research network is committed to the IZA Guiding Principles of Research Integrity.

The Institute for the Study of Labor (IZA) in Bonn is a local and virtual international research center and a place of communication between science, politics and business. IZA is an independent nonprofit organization supported by Deutsche Post Foundation. The center is associated with the University of Bonn and offers a stimulating research environment through its international network, workshops and conferences, data service, project support, research visits and doctoral program. IZA engages in (i) original and internationally competitive research in all fields of labor economics, (ii) development of policy concepts, and (iii) dissemination of research results and concepts to the interested public.
\end{abstract}

IZA Discussion Papers often represent preliminary work and are circulated to encourage discussion. Citation of such a paper should account for its provisional character. A revised version may be available directly from the author. 


\section{ABSTRACT \\ Life Expectancy, Schooling, and Lifetime Labor Supply: Theory and Evidence Revisited ${ }^{*}$}

This paper presents a theoretical and empirical analysis of the role of life expectancy for optimal schooling and lifetime labor supply. The results of a simple prototype Ben-Porath model with age-specific survival rates show that an increase in lifetime labor supply is not a necessary, nor a sufficient, condition for greater life expectancy to increase optimal schooling. The observed increase in survival rates during working ages that follows from the "rectangularization" of the survival function is crucial for schooling and labor supply. The empirical results suggest that the relative benefits of schooling have been increasing across cohorts of US men born 1840-1930. A simple quantitative analysis shows that a realistic shift in the survival function can lead to an increase in schooling and a reduction in lifetime labor hours.

JEL Classification: E20, J22, J24, J26, O11

Keywords: longevity, life expectancy, schooling, lifetime labor supply, rectangularization of the survival function

Corresponding author:

Uwe Sunde

Ludwig-Maximilians-Universität

Seminar für Bevölkerungsökonomie

Schackstr. 4/IV Stock, Raum 413

80539 München

Germany

E-mail: uwe.sunde@econ.Imu.de

\footnotetext{
* We are grateful to Michael Bar, Rauf Boucekkine, Giacomo Calzolari, David de la Croix, Matthias Doepke, Bernd Fitzenberger, Andreas Irmen, Oksana Leukhina, Omar Licandro, Alexander Ludwig, Sebnem Kalemli-Oczan, Giovanni Prarolo, Gesine Stephan, Rodrigo Soares, Rudi Stracke, Tito Pietra, Paolo Vanin and five anonymous referees for extensive comments. We would also like to thank seminar participants at St.Gallen, Munich, the workshop "Towards Sustained Growth" in Barcelona, the LEPAS 2010 workshop in Vienna, the European Workshop on Labor Markets and Demographic Change, the VfS annual meetings in Göttingen and St.Gallen (Population Council), the MPI-Sire workshop on aging, and the 2013 Labor Economics Seminar in Lech for helpful comments and suggestions. Funding from EIEF is gratefully acknowledged.
} 


\section{Introduction}

The increase in life expectancy has been one of the most important demographic changes over the last two centuries. A growing research effort has been devoted to study the implications for individual behavior and economic outcomes. In particular, the literature has found empirical evidence for a positive causal effect of increased life expectancy on individual education attainment, see Bleakley (2007), Jayachandran and Lleras-Muney (2009), and Oster, Shoulson and Dorsey (2013). This evidence is in line with an earlier theoretical literature in which reductions in mortality play a relevant role for the incentives to engage in formal schooling and acquire human capital, see de la Croix and Licandro (1999), Kalemli-Ozcan, Ryder and Weil (2000), Boucekkine, de la Croix and Licandro (2002, 2003), Lagerloef (2003), Soares (2005) and Cervellati and Sunde (2005), among others. The important role of life expectancy for education has been put into question by Hazan (2009) who conjectures that the observed reduction in lifetime labor supply implies a violation of a general, but implicit, necessary condition for longevity to increase schooling 1 The validity of this conjecture, which is relevant for academic research as well as for policy, has not been verified in a life cycle model with a realistic demographic structure, however. This paper contributes a theoretical, empirical and quantitative investigation of the role of changes in age-specific mortality rates for optimal schooling and lifetime labor supply.

Section 2 introduces a prototype Ben-Porath model with a realistic survival law. The theoretical analysis delivers two main results. First, an increase in lifetime labor supply is generally not a necessary, and neither is a sufficient, condition for higher life expectancy to induce an increase in optimal years of schooling 2 Second, the (relative) benefits of schooling increase ceteris paribus following a reduction in mortality at intermediate (working) ages, while the lifespan, that is longevity, by itself may not matter. These results imply that the observation of a reduction in lifetime labor supply does not allow concluding that reductions in mortality should be ruled out as a potential determinant of the observed increase in schooling. The findings rather suggest that the theoretical investigations of the role of life expectancy for lifetime labor supply and education should be based on sufficiently elaborated models that account, in particular, for realistic changes in survival functions.

Section 3 revisits the empirical evidence on life expectancy, schooling and lifetime labor sup-

\footnotetext{
${ }^{1}$ Hazan (2009) concludes that the increase in life expectancy "cannot account for any of the immense increase in educational attainment over the last 150 years"(p. 1857) suggesting that the decline in lifetime labor supply violates a general necessary condition for life expectancy to increase schooling that pertains to the entire literature.

${ }^{2}$ The model nests the framework studied by Hazan (2009) as a special case and shows that an increase in lifetime labor supply is a necessary condition only under a set of seemingly innocuous but counterfactual simplifying assumptions including, in particular, the assumption of a perfectly rectangular survival probability distribution.
} 
ply for cohorts of US men born in the period 1840-1930. The analysis delivers two main results. First, it documents that the observed increase in life expectancy was the result of a process of progressive "rectangularization" of the survival function, which led to sizable reductions in mortality at intermediate (working) ages but left survival rates at young (schooling) ages and the lifespan essentially unchanged $3^{3}$ The analysis also shows that the reduction in expected lifetime labor hours (that affect the benefits of schooling) were associated with even higher reductions in hours of work at school leaving ages (that is the main component of the opportunity cost of school). A second result of the empirical analysis is, consequently, that the relative benefits from schooling have been increasing hand in hand with the increasing life expectancy and schooling. The empirical evidence therefore implies that no obvious violation of the general necessary condition for higher optimal schooling can be detected in the data.

The empirical findings leave open whether the simple prototype Ben-Porath model can generate patterns that are consistent with the empirical observations. This question is addressed in Section 4 by solving the model numerically and performing a simple quantitative exercise that allows isolating the role of the observed reductions in mortality rates. Changes in the survival function like the one experienced by the cohorts born between 1880 and 1930, lead to an increase in optimal schooling as well as a reduction in lifetime labor supply. The higher life expectancy implies that the later cohorts can afford both larger lifetime consumption and larger leisure (and therefore lower lifetime labor supply) because of the income effect associated with the increase in earnings that was due to higher human capital investments. This result illustrates that a reduction in expected total hours of work is not a necessary condition for life expectancy to increase schooling. The findings also suggest that a change in survival rates alone can rationalize a non negligible part of the historical drop in expected total working hours and that the consideration of realistic increases in wages and schooling effectiveness has the potential to explain a large part of the remaining reduction in lifetime labor supply.

\section{Theoretical Predictions}

\subsection{The Model}

Consider a simple prototype Ben-Porath model with a generic survival probability distribution that allows for age-dependent mortality rates. Let us set birth at $t=0$ so that $t$ also represents

\footnotetext{
${ }^{3}$ This is in line with a large body of evidence produced by demographers, see Fries (1980), Gavrilov and Gavrilova (1991) and Wilmoth and Horiuchi (1999), among others, and more recently also by economists, see Strulik and Vollmer (2013) and de la Croix and Licandro (2012).
} 
the age of individuals 4 Denote by $p_{t}$ the unconditional probability of being alive at age $t$. The maximum age that can be reached, implicitly defined by $p_{\bar{T}}=0$, is $\bar{T} \in(0, \infty)$, while life expectancy at birth is denoted by $T$.

Individuals maximize the expected lifetime utility

$$
V=\sum_{t=1}^{\bar{T}} \beta^{t-1} p_{t}\left[u\left(c_{t}\right)+v\left(l_{t}\right)\right],
$$

where $u(\cdot)$ and $v(\cdot)$ are increasing and concave functions of consumption $c$ and leisure $l$, respectively, and $\beta$ is the subjective discount factor.

The total human capital realized by spending the first $S$ years of life at school is given by $\bar{s}(S)=\sum_{1}^{S} g\left(s_{t}\right)$ where $s_{t}=1-l_{t}$ is the time spent at school for $t \leq S$ and $g(\cdot)$ is the production function of human capital with $g^{\prime}(\cdot)>0$ and $g^{\prime \prime}(\cdot) \leq 0$. Human capital maps into earnings according to an earnings function $y(\bar{s}(S))$ with $y^{\prime}(\bar{s}(S))>0$.

Agents work from age $S+1$ until age $R \leq \bar{T}$ and then retire 5 Individuals finance their lifetime consumption by their lifetime labor earnings. There are perfect capital and annuity markets with exogenous interest factor $b$. The individual lifetime budget constraint is therefore given by

$$
\sum_{t=S+1}^{R} b^{t-1} p_{t} L_{t} y(\bar{s}(S))=\sum_{t=1}^{\bar{T}} b^{t-1} p_{t} c_{t},
$$

where $L_{t}=1-l_{t}$ is labor supply for all $S<t \leq R$.

The years of school, $S$, as well as consumption and leisure at each age, $c_{t}$ and $l_{t}$, are chosen optimally to maximize the lifetime utility (1) under the budget constraint (2). The first order conditions for consumption, leisure at school and leisure at work in each period of life are given by,

$$
\begin{aligned}
\beta^{t-1} u^{\prime}\left(c_{t}\right) & =\lambda b^{t-1} & & ; \forall t \\
p_{t} \beta^{t-1} v^{\prime}\left(l_{t}\right) & =\lambda g^{\prime}\left(s_{t}\right) y^{\prime}(\bar{s}(S)) \sum_{t=S+1}^{R} b^{t-1} p_{t} L_{t}(S) & & ; \forall t \leq S \\
\beta^{t-1} v^{\prime}\left(l_{t}\right) & =\lambda b^{t-1} y(\bar{s}(S)) & & ; \forall S<t \leq R .
\end{aligned}
$$

where $\lambda$ is the Lagrange multiplier associated with the budget constraint, (2), and $L_{t}(S)$ denotes optimal labor supply at time $t$ conditional on $S$ years of schooling.

Condition (3) is the Euler equation determining the consumption profile over the life cycle. Condition (4) pins down the optimal time invested in education before entering the labor market,

\footnotetext{
${ }^{4}$ Alternatively, $t=0$ might correspond to the age at which the individual formulates its lifetime plan for consumption, schooling and labor supply, e.g., at age 5 .

${ }^{5}$ Considering an endogenous retirement decision leaves the relevant first order conditions as well as the main results unaffected, as is discussed in the Appendix. For related recent work on the consequences of declining mortality for retirement and savings patterns see Kalemli-Ozcan and Weil (2010) and d'Albis et al. (2012).
} 
that is, for $t \leq S$. Condition (5) characterizes the optimal labor supply after having completed education for $S<t \leq R]^{6}$ The optimal choice of schooling years $S$ is the one that maximizes lifetime utility (1) given the budget constraint (2) and given the optimal path of consumption, leisure while at school and leisure while at work as implied by the first order conditions (3), (4) and $(5)$.

\subsection{Costs and Benefits of Schooling, and Lifetime Labor Supply}

The trade-off faced by individuals when deciding about how long to stay in school, $S$, involves comparing the expected benefits of staying at school for one additional period to the opportunity cost of delaying the entry in the labor market.

The benefits of staying in school at age $S$ (after $S-1$ years of school) are given by the increase in lifetime earnings associated with the higher human capital, which is obtained in the last year at school,

$$
[y(\bar{s}(S))-y(\bar{s}(S-1))] \cdot \sum_{t=S+1}^{R} p_{t} b^{t-1} L_{t}(S) .
$$

Following Hazan (2009), let us introduce the acronym ETWH as a short notation for the expected total (lifetime) hours of work, the second component of the expected benefits from schooling (6),

$$
E T W H:=\sum_{t=S+1}^{R} p_{t} b^{t-1} L_{t}(S) .
$$

Staying in school at $S$ involves an opportunity cost:

$$
y(\bar{s}(S-1)) \cdot p_{S} b^{t-1} L_{S}(S-1)
$$

which is given by the expected loss of labor earnings (that can be obtained with $S-1$ years of schooling and the associated optimal labor supply, $L_{S}(S-1)$ ) due to staying the last period at school, $t=S$, instead of working.

\subsection{Implications}

The analysis of benefits and costs of schooling delivers two relevant implications. First, an increase in lifetime labor supply is neither a necessary, nor a sufficient, condition to observe an increase in optimal schooling. Second, the relative benefits of schooling increase following reductions in mortality at intermediate (working) ages while higher longevity by itself may not matter. Before turning to the analysis of their empirical relevance, let us briefly discuss these implications.

\footnotetext{
${ }^{6}$ Sufficient conditions insuring that (3), (4) and (5) identify a unique interior optimum are $u^{\prime \prime}(\cdot)<0, v^{\prime \prime}(\cdot)<0$ and $y^{\prime \prime}(\cdot)<0$.
} 
The Role of Expected Lifetime Labor Supply, ETWH. Hazan (2009) predicts that an increase in $E T W H$ is a necessary condition for life expectancy to increase schooling. This prediction can be obtained from the theoretical framework introduced above only by imposing additional assumptions. In particular, the consideration of a perfectly rectangular survival probability distribution dramatically limits the role of reductions in mortality by construction because they can only affect the expected lifetime earnings through extending the length of life 7 Further assuming an exponential earnings function, a linear human capital production, and that schooling can be chosen in continuous time leads to the prediction that $g\left(s_{S}\right)=s_{S}=L_{S}$, which effectively implies assuming that school time and work time are perfectly interchangeable in producing utility. Using this prediction to simplify the expressions of benefits and cost of schooling, ETWH is the only component that is left. Accordingly, an increase in lifetime labor hours is, indeed, required to observe an increase in schooling 8 The empirical results in Section 3 document, however, that the simplifying assumptions that are required for the prediction that an increase in $E T W H$ represents a necessary condition are counterfactual.

The theoretical results of the previous section imply that a change in $E T W H$ alone is neither a necessary, nor a sufficient, condition for observing an increase in relative benefits of schooling. A change in demographic or economic conditions (for instance survival rates or returns to schooling) generally influences optimal schooling by altering both the benefits (6) and the costs (7), and not only the expected lifetime labor supply, $E T W H$, which is only one of the components of the benefits.

The Role of Changes in Age-Specific Survival Probabilities. The focus on longevity is made for simplicity in most theoretical studies but, as discussed next, it is a key assumption in the present application where the exclusive focus on changes in the life span is seriously misleading. It is not a change in the length of life, per se, that matters for changes in schooling behavior, but rather the differential change in survival rates during young and working ages.

A comparative-static change in age specific survival rates that occurs only during the schooling period, for $t \leq S$, or after retiring, for $t>R$, has no direct effect on either benefits or

\footnotetext{
${ }^{7}$ Technically, Hazan (2009) assumes that individuals survive with certainty until $\bar{T}$ at which they die with certainty: $p_{t}=1$ for all $t \leq T$ and $p_{t}=0$ for all $t>T$. In this case life expectancy coincides with the life span, $T=\bar{T}$.

${ }^{8}$ In the Appendix we show that the model presented above nests the models studied by Hazan (2006) (with endogenous labor supply) and Hazan (2009) (with exogenous labor supply) as special cases. There we also provide a simple proof that the prediction that an increase in ETWH is a necessary condition can be obtained only by jointly imposing all the simplifying assumptions. This implies, in particular, that only imposing a subset of these assumptions alone, e.g., continuous time or a linear human capital production function, is not enough to obtain a necessary role for $E T W H$.
} 
costs (6) and (7). A reduction in mortality crucially affects the trade-off of optimal schooling if it occurs during working ages, however. To clarify this issue, consider the Gompertz-Makeham (Gompertz, 1825 and Makeham, 1960) function that models mortality rates as increasing exponentially with age $t$,

$$
\mu(t)=A+B e^{\delta t}
$$

where $A$ reflects the age-independent mortality rate and $B$ and $\delta$ are parameters describing the age-dependent mortality process. The corresponding unconditional probability of surviving to age $t$ (assuming that $p(0)=1$ ) is given by

$$
p(t)=\exp \left(-A t-\frac{B}{\delta}(\exp (\delta t)-1)\right)
$$

Changes in the parameters $B$ and $\delta$ of the survival function (9) materialize in changes in agespecific survival rates, life expectancy and longevity. A large body of evidence has documented that these parameters do not change independently, however, but that $\delta$ and $B$ are linked by an inverse relation known as the Strehler-Mildwan correlation (Strehler and Mildvan, 1960) or as the "compensation law" of mortality,

$$
\ln B=\ln M-\delta \bar{T}
$$

where $M$ and $\bar{T}$ are invariant parameters 9 Technically, the increase in life expectancy results from a reduction in the level parameter $B$ coupled with a (compensating) increase in the slope parameter $\delta$ with $\bar{T}$ remaining constant. The result of a compensated reduction in the mortality parameter $B$ is an increase in age-specific survival rates that is hump-shaped, that is, largest for intermediate ages but negligible for young ages and old ages ${ }^{10}$ The existence of the compensation effect is crucial since it implies the well known phenomenon that, since Fries (1980) coined the term, is more informally known as "rectangularization" of the survival function. This process implies that the increases in life expectancy observed historically is mainly due to an increase in the survival probability during prime (working) ages, while the survival rates at young ages and the maximum life span are essentially unchanged.

The rectangularization of the survival function has a relevant comparative statics implication that can be directly derived from the inspection of the expressions for benefits, (6), and costs,

\footnotetext{
${ }^{9}$ Despite its simplicity, the Gompertz-Makeham survival function coupled with the Strehler-Mildvan compensation is probably the most widely used description of age-specific mortality since it represents a surprisingly precise representation of the aging process for humans as well as other species, see Gavrilov and Gavrilova (1991). Section 3 provides a more detailed discussion of the available empirical evidence and performs an estimate of the compensation effect for the US.

${ }^{10}$ Specifically, a "compensated" effect of $B$ implies $\partial p(t) / \partial B<0$ for $t \in(0, \bar{T})$, and $\partial p(t) / \partial B=0$ for $t \rightarrow 0$ and $t \rightarrow \bar{T}$. See Appendix A.2.
} 
(7): the age specific changes in mortality rates have a negligible effect on the opportunity cost of schooling since survival rates at labor market entry, $p(S)$, barely change, but increase the expected benefits that materialize during working ages, $p(t)$ for $t \in(S, R)$. As a result, reductions in mortality may well have played a role for the incentives to acquire schooling. Whether the process of rectangularization was indeed associated with an increase in relative benefits of schooling is ultimately an empirical question to which we turn next.

\section{$3 \quad$ Empirical Evidence}

This section provides empirical evidence on the question whether the historical data are compatible with an increase in relative benefits of schooling in association with the observed increase in life expectancy. The empirical analysis proceeds in two steps. First, in Section 3.1, we investigate the change in the age-specific survival functions of cohorts of US men born between 1840 and 1930. Second, in Section 3.2, we estimate the historical changes of the different components of benefits and costs of schooling: equations (6) and (7). For comparability with the existing literature, the estimation exploits the data used by Hazan (2009) as benchmark ${ }^{11}$ In the analysis we also use the data on schooling and labor hours by Ramey and Francis (2009), who provide a detailed analysis of hours of work and hours of school for the US for more than a century.

\subsection{Rectangularization of the Survival Probability Distribution}

As discussed in Section 2.3, changes in mortality that occur during the process of "rectangularization" and materialize in disproportional increases of survival during intermediate ages, should have a first order effect on schooling. Figure 1, depicts the survival curves for the different cohorts of men born in the US. Figure1(a) depicts the survival rates conditional on reaching age 20 while Figure 1(b) plots the cumulative increase in survival probabilities at different ages across cohorts, compared to the cohort born in 1840. The figures provide a first graphical illustration of the hump-shaped increases in age specific survival rates predicted by the compensation effect. Increases in life expectancy are indeed mostly due to increases in survival probabilities at working ages, whereas the maximum expected lifetime, that is longevity, hardly changed. The pattern of rectangularization is apparent throughout all cohorts 1840-1930, although the increase in survival rates during working ages is most evident for the cohorts born after 1870 .

Insert Figure 1 about here

\footnotetext{
${ }^{11}$ The data are available on the Econometrica website.
} 
A more formal way to document the process of "rectangularization" is by estimating the parameters of the Gompertz-Makeham survival function and verifing the existence of the "compensation law" 12 Specifically, in a first step, we estimate by non-linear least squares the parameters $\delta, A$ and $B$ of the function (9) separately for each cohort of men born 1840-1930 in the US using the respective cohort-specific survival data. In a second step, the parameters $\hat{B}$ and $\hat{\delta}$ estimated for each birth cohort are used to determine the parameters $\bar{T}$ and $M$ of the compensation law, 10, by regressing $\ln \hat{B}$ on $\hat{\delta}$. The results reported in Figure 2 show an almost linear negative relationship between the estimated $\delta$ and $\ln B$, which implies strong evidence in favor of the compensation effect (and therefore the process of rectangularization) being in place. The findings also confirm that the life span hardly changed for the cohorts 1840-1930, despite the substantial increase in life expectancy ${ }^{13}$

Insert Figure 2 about here

The process of progressive rectangularization of the survival function has been documented also by Wilmoth and Horiuchi (1999) for a sample of countries that have undergone the demographic transition and, more recently, by Strulik and Vollmer (2013), for the period 1900-2000 in a large cross-section of countries 14 The same pattern has been documented for the preindustrial period 1000-1900 by de la Croix and Licandro (2012) using a cross-country data set on the mortality of famous individuals. Taken together, the results for the US appear therefore in line with a large, and increasing, body of empirical evidence that suggests that the existence of a progressive historical process of rectangularization of the survival function across countries is a robust stylized fact.

\subsection{Benefits and Costs of Schooling}

Estimates of Hours of School and Work at Labor Market Entry Ages. As a preliminary investigation, Figure $3(\mathrm{a})$ depicts the average hours per week that individuals aged 14-17 spent at school and at work since 1900 using period data from Ramey and Francis (2009) 15 The figure shows that hours of school and work at labor market entry differ and change in opposite

\footnotetext{
${ }^{12}$ In a previous version of the paper, Cervellati and Sunde (2010), we estimated the alternative parametric survival probability function proposed by Boucekkine, de la Croix and Licandro (2003), with similar results.

${ }^{13}$ The results of the non-linear estimation are reported in Table 1 in the Appendix. The estimated parameters of 10 are $\bar{T}=98.45$ and $\ln M=-0.967$. This result is very similar to the figure of $\bar{T}=95$ obtained by Gavrilov and Gavrilova (1991) from estimates of the compensation law using more than 200 historical life tables.

${ }^{14}$ The findings by Strulik and Vollmer (2013) document that human life span has been approximately constant until about the 1950s, which is consistent with the compensation effect observed in US. Only in the last decades they find a moderate increase in longevity in terms of the life span in the more developed countries.

${ }^{15}$ We also plot the average hours devoted to market work, as well as the total average time per week devoted to school, market work and home production. The data are constructed using information on the average days per
} 
directions. The figure also documents a steady increase in time devoted to school and a steady decrease in labor supply at young ages (with leisure staying roughly constant). Figure 3(b) presents the same pattern for the averages computed for the different birth cohorts for which data are available, starting with the cohort born in 1880 16 A similar pattern has been found by Ramey and Francis (2009) over the past century.

\section{Insert Figure 3 about here}

These stylized facts document that the prediction that the time spent at school, $s_{S}$, and at work at the age of labor market entry, $L_{S}$, are exactly equal is counterfactual ${ }^{17}$ A relevant implication of this evidence is that to evaluate the change in the trade-off faced by subsequent cohorts, one should estimate the relative benefits of schooling considering all the components of both benefits (6) and costs (7), and not only the changes in ETWH.

Estimates of Work Hours During the Life Cycle. From the discussion in Section 2, the hours of work affect both the expected benefits and the opportunity cost of increasing schooling. Hazan (2009) aggregates labor hours over the entire lifetime (weighted by the age-specific survival probability as well as the probability of being in the labor market) to get the empirical equivalent of $E T W H$. He then investigates the empirical changes in life expectancy and hours of work for the successive 10-year cohorts born in the period 1840-1970 in the U.S. and documents that the increase in life expectancy goes hand in hand with a reduction in ETWH. We complement the analysis by explicitly considering also the change in the hours of work at school leaving age, which is the main component of the opportunity cost of delaying school.

Figure 4 (a) displays the reduction in the estimates of $E T W H$ for $b=1$ for the cohorts born between 1840 and 1930 ${ }^{18}$ Assuming, as in Hazan (2009), that ETWH is the only relevant school year attended by a person enrolled in a school and on the average hours spent in class and on homework per day attended. We do not weight this number by the fraction of 14-17-year-old that are enrolled in school (as done by Ramey and Francis (2009)) since we are considering $s_{S}$ as a measure of the effectiveness of an additional period in school for an individual that is just about to leave school (in the optimum). This delivers a conservative measure of the increase in $s_{S}$.

${ }^{16}$ The cohort 1890 comprises all individuals born 1886-1895. To match this, we use the period data from 1904 to 1907 for the 14-17-year-old to compute the average hours of school and market work for this cohort. For the cohort born 1900 we use the period data from 1914-1917, and so on. For the cohort born 1880, we compute the hours using period information from the years 1900-1904. A similar upward trend in time spent in school is found when restricting attention to age groups 18-24, and when considering men and women separately, see also Ramey and Francis (2009). We report further evidence using alternative data below.

${ }^{17}$ As discussed in Section 2.3 and derived formally in Appendix A this restriction needed to simplify the first order condition predicting that an increase in $E T W H$ is a necessary condition to observe an increase in schooling. The data shows that the respective components of the benefits and the costs differ and do not cancel out in the general version of the model, and in fact they change across cohorts in opposite directions in the data.

${ }^{18}$ The data correspond to the benchmark estimates reported in Figures 7 and 10 in Hazan (2009). 
component of relative benefits from education, and that life expectancy is the only variable that changes during the observation period, one would therefore conclude that the first order condition for increasing schooling is violated. The figure complements the analysis by showing that the hours of work at labor entry declined as well, however, which implies that also the opportunity cost of schooling has decreased. Figure 4 (b) plots the benefits and costs normalized to the level of the cohort born in 1840 , as well as the ratio between the two. The data show that the reduction in the opportunity cost is in fact larger than the reduction in expected total hours of work. As a result, the ratio of the two increased, at least since 1870 .

Insert Figure 4 about here

Figures 4(c) and (d) show that the result is not driven by considering a discount rate of zero. In fact, the consideration of a positive discount rate reinforces the increasing pattern, tilting the ratio in favor of schooling, because the reduction in benefits (which occurs later in life) is discounted more than the reduction in opportunity costs (which accrue at the moment of entering the labor market). These results are robust to extensive checks 19

This evidence clarifies the importance of considering the change in labor hours at school leaving age, which is the main component of the opportunity cost, in addition to the change in ETWH, which only represents one component of the expected benefits. Historically, the largest reduction in hours of work concerned hours at labor market entry. This is one of the stylized facts produced by Ramey and Francis (2009) and has also been noted by Hazan (2009), who points out that "the reason for the declining trend [in ETWH] is that although average hours of work across men and women were virtually unchanged for those aged 22-54, hours fell substantially for the younger and older age groups." (p. 1852). A key implication of the patterns depicted in Figures 4 (and 7 in the Appendix) is that the relative benefits of schooling might have increased relative to the cost component, not decreased, as one might conclude from a look at the drop in ETWH alone.

Estimates of Schooling Hours. The second component of the benefits of schooling (6) besides $E T W H$ relates to the increase in earnings $[y(\bar{s}(S))-y(\bar{s}(S-1))]$ due to the higher level of human capital that the individual has acquired by spending the additional time $s_{S}$ at school.

Insert Figure 5 about here

\footnotetext{
${ }^{19}$ The results from robustness checks that include and extend the robustness checks conducted by Hazan (2009) are reported in Appendix. Figure 7 shows that the same patterns emerge for period data as well as for cohort and period data for all individuals rather than only for men. Figure 8 and 9 show that the results are robust to the consideration of discounting and to the use of estimates computed at age 10 rather than 20, respectively.
} 
Figure 5 complements the evidence reported in Figure 3 by showing the hours invested in schooling before entry into the labor market ${ }^{20}$ This measure, which has clearly been increasing substantially after 1870, corresponds to the time spent in education and hence represents the input in the production of human capital. The increase in earnings associated with this time investment in schooling, and therefore in the expression for the marginal benefits of schooling, depends on the actual function of human capital $g(\cdot)$, which is unobservable. This does not preclude the interpretation of the evidence of Figure 5 , however, since the increase in hours of schooling $s_{S}$ implies an increase in the production of human capital at labor market entry for any increasing human capital production function, $g\left(s_{S}\right)^{21}$ As a result, the consideration of schooling hours implies an even more pronounced increase in the estimate of the relative benefits across cohorts (see Figure 4 and 5 , 22

Estimates of Life Expectancy, Benefits and Costs of Schooling. Figure 6(a), which replicates Figure 1 in Hazan (2009), plots the data on life expectancy corresponding to Figure 1(a) as well as the average years of schooling for the cohorts born 1840-1930. This figure documents that life expectancy increased throughout all cohorts, while education in terms of the average years of schooling increased substantially for cohorts of men born after 1880 .

Insert Figure 6 about here

Figure 6(b) plots the average years of schooling and the change in the relative benefits of school, obtained by combining the estimates depicted in Figure 4 and Figure $5{ }^{23}$ The figure illustrates that the increase in years of schooling after 1880 goes hand in hand with the change in the estimates of relative benefits, which also display a sizable increase after 1880 .

\footnotetext{
${ }^{20}$ Data from Ramey and Francis (2009) are only available for 1880 onwards.

${ }^{21}$ The literature generally assumes a production function of human capital that is strictly increasing and concave in time devoted to school. For instance, Ben-Porath (1967) and Blinder and Weiss (1976) assume functions $g(\cdot)$ with $g(0)=0, \partial g(\cdot) / \partial s>0$ and $\partial^{2} g(\cdot) / \partial s^{2}<0$.

${ }^{22}$ For lack of data on earlier cohorts, we assume that for the cohorts born before $1880 s_{S}$ was at the level of the cohort born in 1880 . The same pattern emerges also for age groups 18-24, and for males and females separately (see Ramey and Francis, 2009, in particular their Figures 3 and Table 3).

${ }^{23}$ The estimates presented in Figure 6(b) are based on the data on ETWH by age 70 depicted in Figure 4 (a) and the data on hours data for ages 18-24 in Figure 5(a). The increase would be larger for the alternative estimates presented in Figure 7. Moreover, the assumption that school intensity remained unchanged until the cohort born 1880 also implies a conservative estimate since any increase in schooling inputs in cohorts born prior to 1880 would tilt the ratio further in favor of the benefits.
} 


\section{A Simple Quantitative Exercise}

Theoretically, an increase in survival probabilities during working ages leads, ceteris paribus, to higher relative benefits of schooling (see Section 2.3). The empirical analysis in Section 3 has documented that the observed increases in life expectancy are due to a progressive rectangularization of the survival function and are associated with increasing benefits of schooling for the cohorts of US workers born after 1880. An open question is whether a simple prototype BenPorath model can generate quantitative patterns that are consistent with the patterns observed in historical data. We address this question by solving the model numerically and performing a simple quantitative exercise that allows isolating the effect of the observed increase in survival probabilities.

\subsection{A Numerical Version of the Model}

To solve the model presented in Section 2 numerically, we need to pin down the functional forms of the utility and earnings functions and set the values of the parameters. Consider a CIES specification for the utility function (1),

$$
u\left(c_{t}\right)+v\left(l_{t}\right)=\frac{c_{t}^{1-\sigma}-1}{1-\sigma}+\frac{l_{t}^{1-\sigma}-1}{1-\sigma}
$$

with $\sigma>0$, as well as an exponential version of the earnings function,

$$
y(\bar{s}(S))=w \cdot e^{\gamma \theta(\bar{s}(S))}
$$

where, following Hazan (2009), $e^{\theta(\cdot)}$ is a standard representation of the Mincerian earnings function, with $\theta(\bar{s}(S))=[\bar{s}(S)]^{\alpha}$ with $\alpha<1$ and $\bar{s}(S)=\sum_{1}^{S} s_{t}$. Recall that $s_{t}=\left(1-l_{t}\right) \leq 1$ is the time devoted to school for each $t \leq S$. The parameter $w$ is a scaling factor related to earnings (like, e.g., a wage rate) while $\gamma$ is a scaling factor related to the productivity of the investment in schooling (like e.g. the efficiency of the schooling system) ${ }^{24}$ The budget constraint is as in (2).

We set $\sigma=2$ following the literature (see Lucas, 2003, Rogerson and Wallenius, 2009, and Chetty et al., 2012) and assume zero discounting, so that $\beta=b=1$, as in Hazan (2009). As benchmark we normalize both the wage and the productivity of schooling, $w=\gamma=1$. We set $\alpha=2 / 3$ to match an initial level of schooling years that is in line with the data for the low life expectancy scenario, as discussed below. It is worth noting that this functional specification and parametrization of the model satisfies all the assumptions made by Hazan (2009), including the consideration of a linear (identity) production function of human capital $g(s(t))=s(t)$ for

\footnotetext{
${ }^{24}$ For the background and empirical relevance of this specification see Lemieux (2006) or Polachek (2007).
} 
all $t \leq S$. The only difference is that we consider the model in discrete time (which is consistent with the discrete nature of the data and allows for solving the model numerically) and, most importantly, with a realistic survival probability distribution, as is discussed below.

The solution of the model is given by the number of schooling years $S$ that maximizes the indirect utility obtained by evaluating (1) at the optimal paths of consumption and leisure that are determined by (3), (4) and (5). With the functional forms (11) and (12), the solution is unique ${ }^{25}$ From (3) and (5), $\beta=b$ implies that the optimal path of both consumption and labor supply is flat: $c_{t}=c$ for all $0<t \leq \bar{T}$ and $L_{t}=L$ for all $S<t \leq R$ (see also the Appendix) ${ }^{26}$

Practically, for any given $S$ the determination of optimal work hours $L$ and schooling hours $s_{t}=1-l_{t}$ (for each $t \leq S$ ) requires solving the non-linear system of $(S+1)$ equations ( $S$ equations of the type (4) for all $t \leq S$, as well as one equation (5) for optimal hours of work) in the $(S+1)$ unknowns $\left\{l_{1}, \ldots, l_{S}, L\right\}$. Procedurally, we first solve numerically this non-linear system to pin down the optimal consumption and leisure decisions for all possible periods of schooling, $S$. The optimal schooling decision is then identified by the $S$ that maximizes lifetime utility when computed at the respective optimal consumption and leisure (schooling intensity and labor supply) paths.

Age Specific Survival Rates. The lifetime is divided in nine periods each corresponding to ten years. Assuming that school starts at age five, the model can be interpreted as covering the individual life cycle from age 5 to 95 . Agents are assumed to retire after the seventh period of their life, which corresponds to age 7522 To investigate the role of life expectancy, we consider the actual age-specific survival probabilities. Specifically, the unconditional probabilities correspond to the geometric average of the survival probability rates for each age bracket (e.g $[26,35])$ from the data depicted in Figure 1(a) for the cohorts born in 1880 and 1930. Consistent with the discussion in Section 3.1, the probability distribution of 1930 differs from the one of 1880 mainly in terms of the larger survival probabilities during prime (working) ages, but not

\footnotetext{
${ }^{25}$ Notice that the earnings function $[12$, that follows Hazan (2009), is not necessarily concave. As discussed in footnote 6 concavity is a sufficient (but not a necessary) condition for the uniqueness of the interior solution. The numerical solution procedure ensures that a global maximum is identified.

${ }^{26}$ Consumption smoothing and a flat labor supply would not be possible in equilibrium in the presence of capital market imperfections (e.g., liquidity constraints) or imperfect annuity markets. Sheshinski (2009) and Hansen and Lonstrup (2012) study the complementarity between reductions in mortality rates and the reduction in financial market imperfections, which allows individuals to better reap the benefits of reductions in mortality rates by smoothing their expected lifetime labor income.

${ }^{27}$ We take retirement at age 75 since this is the first period in which the probability of remaining in the labor market drops below 10 percent in the data, while at 65 it is still above 40 percent for all cohorts of men born between 1840 and 1930, see Figure 5 in Hazan (2009). The results are equivalent if one sets retirement at age 65.
} 
in terms of the maximum age that can be reached 28

\subsection{Results}

The analysis proceeds in two steps. First, we solve the benchmark model for the survival function of the cohort of workers born in 1880 and in 1930, respectively. This counterfactual exercise allows us to study the effect of the change in the survival function by performing a controlled experiment in which the model economy is identical, except for the survival function. Second, in line with the available empirical evidence discussed below, we assume that the cohort of 1930 differs from the one of 1880 also in terms of wages, $w$, or in terms of productivity of schooling inputs, $\gamma$, or both. This allows us to study the joint effects of life expectancy, wages and schooling effectiveness.

The Role of Age Specific Survival Rates. When solving the model with the survival function faced by the cohort born in 1880 , one period of schooling is optimal ${ }^{29}$ To isolate the effect of an increase in survival rates, we next solve the very same model (with all parameters unchanged) for the survival rates faced by the cohort born in 1930. Under this parametrization, optimal schooling is two periods and the equilibrium lifetime labor supply, $E T W H$, is about 8 percent lower 30 Recall that, having assumed a fixed retirement at age 75 , the maximum time that can be devoted to work cannot increase by construction. This illustrates that the larger incentives to invest in schooling are due to the increase in survival probability during working ages and not in the maximum spell of life.

For the workers born in 1930 more schooling is optimal, in spite of the reduction in ETWH, since the income effect associated with the higher life expectancy is large enough for them to afford both higher lifetime consumption and higher leisure while at work. This cohort exhibits a 20 percent higher life expectancy and spends 85 percent more time in school than the cohort

\footnotetext{
${ }^{28}$ As shown in Section 3 , the increase in both schooling years and the relative benefits of schooling is notable after the cohort born in 1880 the historical US data. We therefore take that cohort as the benchmark for the quantitative analysis. The corresponding vector of survival probabilities for each of the ten-year age brackets are $P_{1880}=(1 ; 0.99 ; 0.93 ; 0.86 ; 0.77 ; 0.66 ; 0.45 ; 0.2 ; 0.04)$ and $P_{1930}=(1 ; 0.997 ; 0.98 ; 0.95 ; 0.9 ; 0.8 ; 0.6 ; 0.3 ; 0.09)$. For both distributions the probability of surviving beyond age 95 (which is the maximum age assumed in the simulation of the model) is essentially zero and the maximum age that can be reached is unchanged. Also the survival probability at young ages displays very minor increases across cohorts (in the range of 0.05).

${ }^{29}$ Recall that this is the case by construction since, as discussed above, the level of $\alpha=2 / 3$ is calibrated to get an optimal schooling of one period for 1880 in line with the data. The average years of schooling for cohorts of men born before 1880 was around 8 years, and increased by more than sixty percent in the next half a century to more than 13 years for the cohort born in 1930, see Figure 6

${ }^{30}$ Restricting attention to the intensive margin of schooling only, Strulik and Werner (2012) also find that an increase in health can lead to an increase in schooling incentives and a reduction in lifetime labor supply.
} 
of 1880 . The per period earnings of the 1930-cohort are 42 percent higher even though wages and school productivity are assumed to be unchanged ${ }^{31}$

The Role of Wages and Schooling Productivity. The changes in schooling years and lifetime labor supply observed in historical data are probably not only related to changes in life expectancy, but also to changes other relevant dimensions such as wages or the effectiveness of the schooling system. Changes in both of these dimensions also affect the returns to human capital investments. To explore the impact of these variables, assume that, compared to those born in 1880, the cohort born in 1930 faces higher survival rates and wages that are twenty percent higher ${ }^{32}$ Compared to the baseline scenario, where wages are kept at the same level for both cohorts, the optimal schooling decision in terms of school periods is unchanged, but the larger income effect leads to further reduction in $E T W H$ by 4 percent and to a further increase in per period earnings by about 23 percent in the 1930 cohort compared to the 1880 -cohort 33

Finally, consider also a 20 percent increase in the productivity of schooling in the cohort born in 1930 compared to the cohort born in 1880. This leaves the optimal schooling years unchanged, but leads to a further 4 percent drop in $E T W H$ and to a further 40 percent increase in per period earnings for the 1930 cohort. The results suggest that if the cohort born in 1930 faced, in addition to its higher life expectancy, a 20 percent higher wage as well as a 20 percent higher school productivity than the cohort born in 1880, it would enjoy about twice as large period earnings and would have to have a lifetime labor supply, ETWH, 15 percent lower than the workers of the cohort born in 188034

\footnotetext{
${ }^{31}$ Also as discussed in Section 2 and analytically derived in the Appendix, optimal hours of work and study do not coincide and move in opposite directions. Per period consumptions is 17 percent higher since the increase in lifetime earnings (by 31 percent) is larger than the increase in life expectancy (20 percent).

${ }^{32}$ Recall that in the baseline scenario the parameters of the earnings function $[12, w$ and $\gamma$, have been set equal to 1 as in Hazan (2009). The two cohorts are now assumed to differ both in terms of the survival probability distribution as well as wages, which are set to $w_{1880}=1$ and $w_{1930}=1.2$, respectively. This is a conservative estimate of the overall increase in wages over half a century. For instance, Field (2009) reports estimates of TFP growth over the period 1870-1930 of above 1.2 percent per year, and suggests that growth rates of labor productivity might have been even higher (see also Field, 2011). Earnings more than doubled over the period 1879 to 1919 in the US (see, for instance, Rosenbloom, 1996).

${ }^{33}$ Most of the increase in earnings is due to the increase in wages rather than the increase in human capital. In fact, higher wages tend to discourage investments in human capital and lead to a reduction of about 5 percent in the total time spent in school.

${ }^{34}$ This scenario involves setting both $w_{1930}=1.2$ and $\gamma_{1930}=1.2$. According to Rangazas (2002), primary and secondary public education expenditures per pupil increased more than fourfold over the period 1880 to 1930 , so that this is likely to be a conservative parameterization. If the productivity and schooling effectiveness were 40 percent higher (so that $w_{1930}=1.4$ and $\gamma_{1930}=1.4$ ), then $E T W H$ would be 24 percent lower, and the per period earnings would be about three times larger for the cohort born in 1930 compared to the cohort born in 1880 .
} 
This simple quantitative exercise illustrates that a realistic shift in the survival function can generate patterns that are in line with those in the data even in the simplest version of the Ben-Porath model. In particular, the results show that reduction in mortality rates at working ages can generate an increase in schooling and labor earnings together with a drop in ETWH 35 The results suggest that a change in survival rates alone can rationalize a non negligible part of the observed drop in expected total working hours and that the consideration of realistic increases in wages and schooling effectiveness have the potential to explain a large part of the remaining reduction in lifetime labor supply.

\section{Concluding Remarks}

This paper has studied the role of life expectancy for optimal schooling and lifetime labor supply in a simple prototype Ben-Porath model with age specific survival rates. The theoretical results show that an increase in lifetime labor supply is neither a necessary, nor a sufficient, condition to observe an increase in optimal schooling following a shift in the survival probability distribution. The comparative statics analysis shows that it is not longevity per se that matters for the incentives for schooling but rather the reductions in working age mortality rates that follows from the widely documented process of "rectangularization" of the survival probability distribution. The empirical results for the US in the period 1840-1930, show that the estimates of the relative benefits from schooling have been increasing over time despite the reductions in lifetime labor supply. A simple quantitative analysis of the prototype model illustrates that a realistic shift in the survival function can lead to an increase in schooling and a reduction in lifetime labor hours. The income effect associated with higher lifetime earnings implies that workers can enjoy both higher lifetime consumption and leisure.

The analysis in this paper can be seen as a first step towards a more comprehensive investigation of the role of changes in age specific survival rates for optimal schooling and lifetime labor supply. For comparability with the literature, the analysis has restricted attention to a simplified model of the life cycle. The results suggest some fruitful directions for future research. The first is the consideration of learning on the job and depreciation of human capital with age that are crucial for the life cycle path of wages and labor supply ${ }^{36}$ Second, the framework could

\footnotetext{
${ }^{35}$ The empirical estimates of the drop in ETWH in the period 1880-1930 range between 5 and 30 percent. See Section 3 and Figures 3 and 7 Specifically, the drop ranges from 12 to 15 percent for cohort estimates (Figures 7, 8 and 9 in Hazan, 2009), from 3 to 11 percent for period estimates (Figures 12 and 13 in Hazan, 2009). The highest estimate is 35 percent (Figure 11 in Hazan, 2009). Depending on the data one prefers, the numerical exercise suggests that the increase in life expectancy alone therefore can explain between 25 and 100 percent of the observed drop in ETWH.

${ }^{36}$ These important elements, which imply a much richer and realistic path of life cycle choices, were explicitly
} 
be extended to the analysis of optimal fertility choices, that have been empirically documented to be crucially intertwined with schooling decisions ${ }^{37}$ Third, the model could be generalized by considering the determination of wages in a general equilibrium setting with physical capital 38 The explicit consideration of these issues appears relevant for a deeper understanding of the link between mortality, education and lifetime labor in a long run perspective and to improve the quantitative fit of model and data.

\section{References}

BenPorath, Y. (1967): "The Production of Human Capital and the Life Cycle of Earnings," Journal of Political Economy, 75(4), 342-365.

Bleakley, H. (2007): "Desease and Development: Evidence from Hookworm Eradication in the American South," Quarterly Journal of Economics, 122(1), 73-117.

Blinder, A. S., ANd Y. Weiss (1976): "Human Capital and Labor Supply: A Synthesis," Journal of Political Economy, 84(3), 449-472.

Boucekkine, R., D. De la Croix, and O. Licandro (2002): "Vintage Human Capital, Demographic Trends, and Endogenous Growth," Journal of Economic Theory, 104(2), 340375 .

(2003): "Early Mortality Declines at the Dawn of Modern Growth," Scandinavian Journal of Economics, 105, 401-418.

Cervellati, M., and U. Sunde (2005): "Human Capital, Life Expectancy, and the Process of Development," American Economic Review, 95(5), 1653-1672.

(2010): "Longevity and Lifetime Labor Supply: Evidence and Implications Revisited," University of Bologna, mimeo.

(2011): "Life Expectancy and Economic Growth: The Role of the Demographic Transition," Journal of Economic Growth, 16, 99-133.

(2013): "The Economic and Demographic Transition, Mortality, and Comparative Development," CEPR DP, 9337.

Chetty, R., A. Guren, D. Manoli, and A. Weber (2012): "Does Indivisible Labor Explain the Difference between Micro and Macro Elasticities? A Meta-Analysis of Extensive Margin Elasticities," in NBER Macroeconomics Annual, forthcoming.

D'Albis, H., S.-H. P. LaU, and M. Sanchez-Romero (2012): "Mortality Transition and Differential Incentives for Early Retirement," Journal of Economic Theory, 147(1), 261-283.

de la Croix, D., and O. Licandro (1999): "Life Expectancy and Endogenous Growth," Economics Letters, 65, 255-263.

\footnotetext{
considered already in the early literature. See Ben-Porath (1967) and Blinder and Weiss (1976).

${ }^{37}$ Cervellati and Sunde $(2011,2013)$ and de la Croix and Licandro (2013) propose theoretical frameworks to study the link between education and fertility but only in the context of a deterministic longevity.

${ }^{38}$ The effect of mortality on income and lifetime labor is likely to be even more pronounced since the endogenous increase in human capital can mitigate adverse effects of reduced labor hours on capital returns. See Ludwig, Schelkle and Vogel (2012).
} 
(2012): "Longevity of Famous People from Hammourabi to Einstein," Barcelona GSE Working Paper, 666.

(2013): "The Child is Father Of the Man: Implications for the Demographic Transition*," The Economic Journal, 123(567), 236-261.

Field, A. J. (2009): "U.S. Economic Growth in the Gilded Age," Journal of Macroeconomics, 31(1), 173-190.

(2011): "Chained Index Methods and Productivity Growth during the Depression," mimeo, SIEPR, Stanford Institute for Economic Policy Research.

Fries, J. (1980): "Aging, Natural Death, and the Compression of Morbidity," New England Journal of Medicine, 303(3), 130-135.

Gavrilov, L., and N. Gavrilova (1991): The Biology of Human Life Span: A Quantitative Approach. Harwood Academic Publishers, London.

Gompertz, B. (1825): "On the nature of the function expressive of the law of human mortality, and on a new mode of determining the value of life contingencies," Philosophical Transactions of the Royal Society of London, 115, 513-583.

Hansen, C. W., and Lonstrup (2012): "Can higher life expectancy induce more schooling and earlier retirement?," Journal of Population Economics, 25(4), 1249-1264.

HAZAN, M. (2006): "Longevity and Lifetime Labour Input: Data and Implications," CEPR Discussion Paper, 5963.

(2009): "Longevity and Lifetime Labour Supply: Evidence and Implications," Econometrica, 77(6), 1829-1863.

Jayachandran, S., And A. Lleras-Muney (2009): "Life Expectancy and Human Capital Investments: Evidence from Maternal Mortality Declines," Quarterly Journal Economics, 124(1), 349-398.

Kalemli-Ozcan, S., H. E. Ryder, and D. N. Weil (2000): "Mortality Decline, Human Capital Investment, and Economic Growth," Journal of Development Economics, 62, 1-23.

Kalemli-Ozcan, S., and D. Weil (2010): "Mortality Change, the Uncertainty Effect, and Retirement," Journal of Economic Growth, 15, 65-91.

LagerlöF, N.-P. (2003): "From Malthus to Modern Growth: Can Epidemics Explain the Three Regimes?," International Economic Review, 44(2), 755-777.

Lemieux, T. (2006): "The Mincer Equation Thirty Years after Schooling, Experience, and Earnings," in Jacob Mincer: A Pioneer of Modern Labor Economics, ed. by S. Grossbard.

Lucas, R. E. (2003): "Macroeconomic Priorities," American Economic Review, 93(1), 1-14.

Ludwig, A., T. Schelkle, and E. Vogel (2012): "Demographic Change, Human Capital and Welfare," Review of Economic Dynamics, 15(1), 94-107.

Makeham, W. (1860): "On the law of mortality and the construction of annuity tables," Journal of the Institute of Actuaries, 8, 301-310.

Oster, E., I. Shoulson, and R. Dorsey (2013): "Limited Life Expectancy, Human Capital and Health Investments," American Economic Review, forthcoming. 
PolacheK, S. (2007): "Earnings Over the Lifecycle: The Mincer Earnings Function and Its Applications," IZA Discussion Paper, 3181.

Ramey, V. E., and N. Francis (2009): "A Century of Work and Leisure," American Economic Journal: Macroeconomics, 1(2), 189-224.

Rangazas, P. (2002): "The Quantity and Quality of Schooling and U.S. Labor Productivity Growth (1870-2000)," Review of Economic Dynamics, 5, 932-964.

Rogerson, R., and J. Wallenius (2009): "Micro and macro elasticities in a life cycle model with taxes," Journal of Economic Theory, 144, 2277-2292.

Rosenbloom, J. L. (1996): "Was There a National Labor Market at the End of the Nineteenth Century? New Evidence on Earnings in Manufacturing," Journal of Economic History, 56(3), 626-656.

Sheshinski, E. (2009): "Uncertain Longevity and Investment in Education," CESifo Working Paper, 2784.

Strehler, B., And A. Mildvan (1960): "General Theory of Mortality and Aging," Science, 123(3428), 14-21.

Strulik, H., And S. Vollmer (2013): "Long-Run Trends of Human Aging and Longevity," Journal of Population Economics, forthcoming.

Strulik, H., And K. Werner (2012): "Life Expectancy, Labor Supply, and Long-Run Growth: Reconciling Theory and Evidence," mimeo, University of Göttingen.

Wilmoth, J. R., And S. Horiuchi (1999): "Rectangularization Revisited: Variability of Age at Death Within Human Populations," Demography, 36(4), 475-495. 


\section{Figures and Tables to be Included in the Text}

- Figure 1: Change in Age Specific Survival Probability Distribution, US 1840-1930;

- Figure 2 : Estimation of the Compensation Effect with Gompertz-Makeham Law of Mortality, US 1840-1930;

- Figure 3. Hours of School and Work at Labor Market Entry Ages, US 1900-2000 (period data) and 1880-1930 (cohort data);

- Figure 4: Change in Benefits and Costs of Schooling, US 1840-1930;

- Figure 5: Evolution of Total Hours of Schooling, US 1840-1930;

- Figure 6: Life Expectancy, Relative Benefits of Schooling and Average Years of Schooling, US 1840-1930;

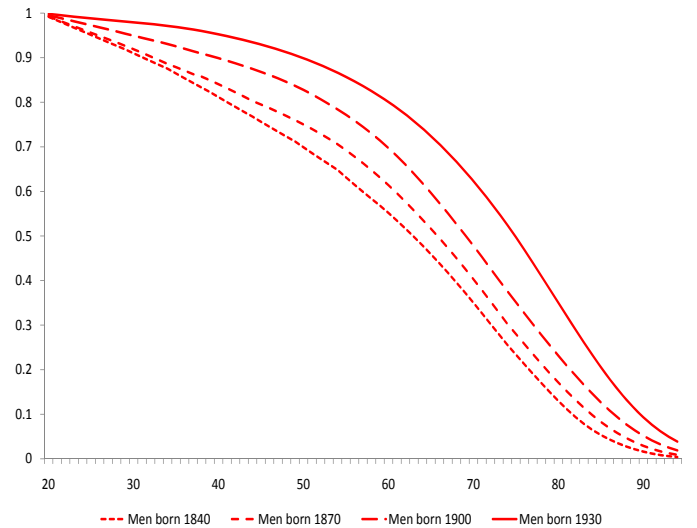

(a) Survival Probability conditional on Reaching Age 20 for Men Born in $1840,1870,1900$, and 1930

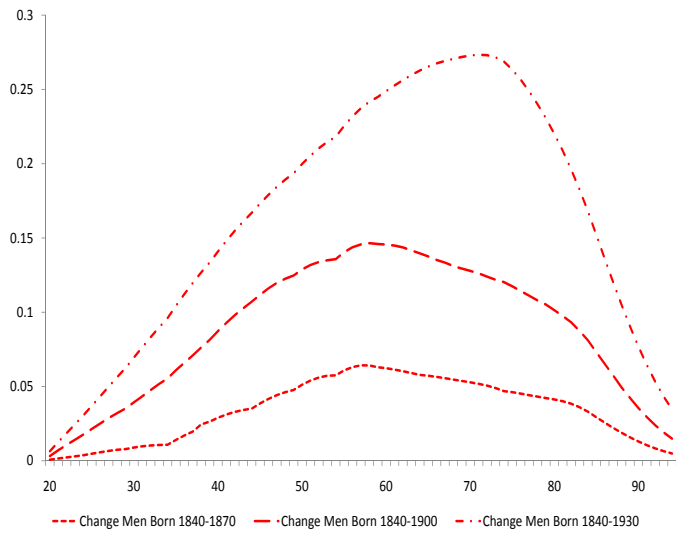

(b) Changes in Survival Probability across Cohorts by Age

Panel (a) is a replication of Figure 2 of Hazan (2009) for the four cohorts born 1840, 1870, 1900 and 1930. See main text for details. Panel (b) shows the respective changes in age-specific survival probabilities between these cohorts.

Figure 1: Change in Age Specific Survival Probability Distribution, US 1840-1930 


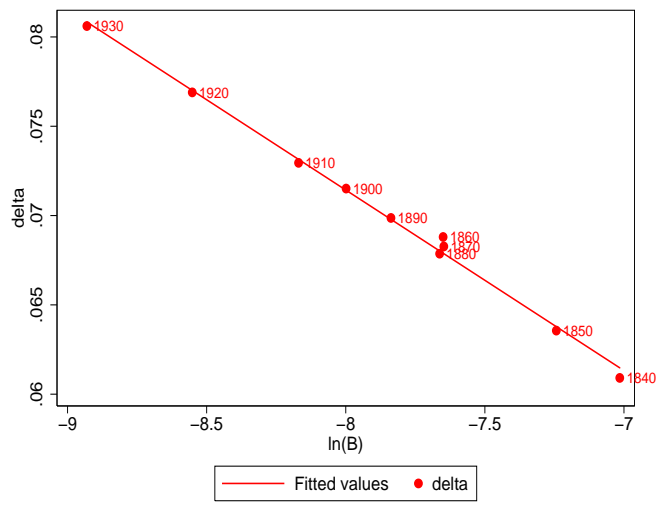

(a) Mortality during ages $20-100$

The Figure plots estimates of the parameters $\delta$ and $\ln B$ of the Gompertz-Makeham survival function 9 for the cohorts 1840-1930. Estimates are based on observations of mortality for ages 20 to 100 .

Figure 2: Estimation of the Compensation Effect with Gompertz-Makeham Law of Mortality, US $1840-1930$

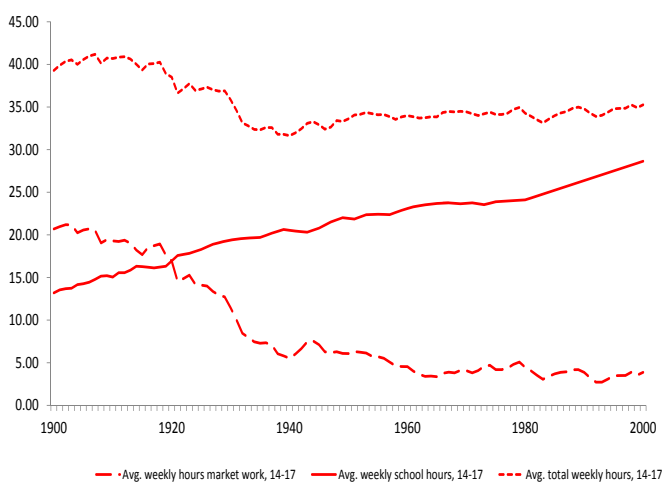

(a) Period Estimates

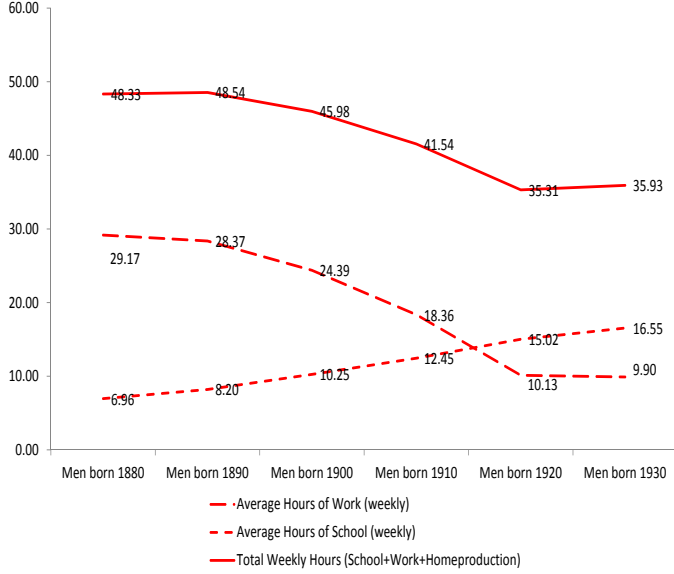

(b) Cohort Estimates

Panel (a) is a replication of Figure 3A of Ramey and Francis (2009) that uses information on weekly hours of work at ages 14-17, but excluding information on enrolment. Panel (b) is an imputation for birth cohorts using the data from panel (a). See text for details.

Figure 3: Hours of School and Work at Labor Market Entry Ages for US, 1900-2000 (period) and 1880-1930 (cohort) 


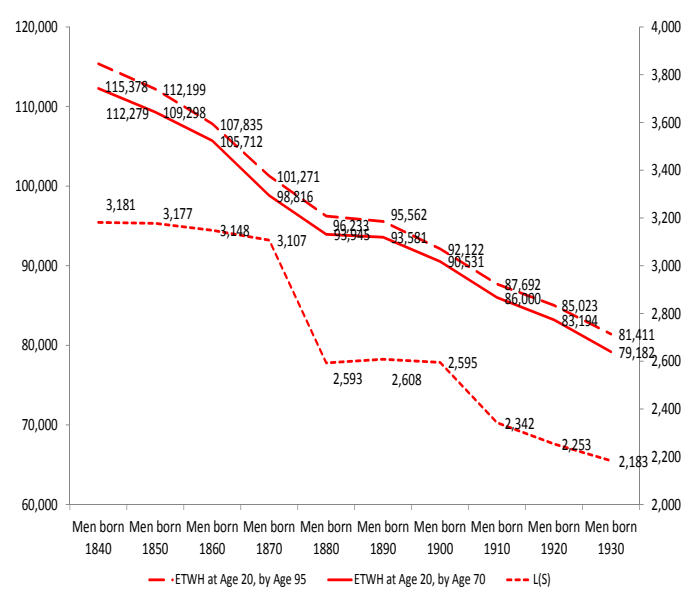

(a) Absolute Changes

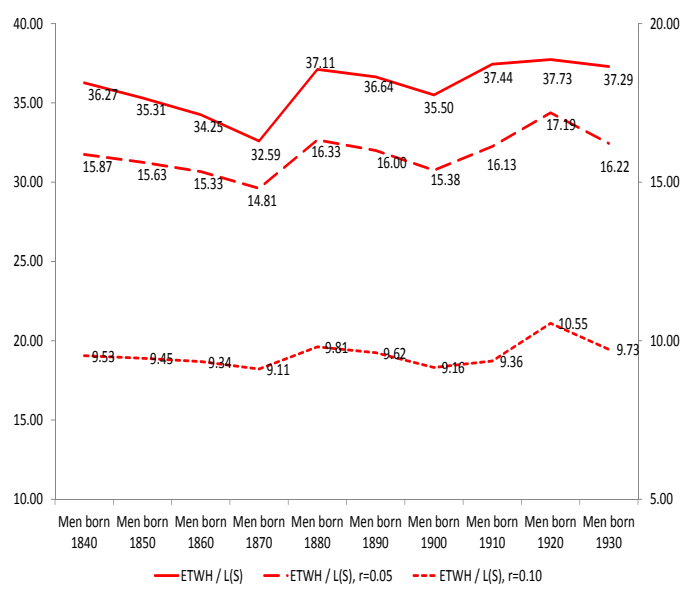

(c) Relative Changes With Discounting

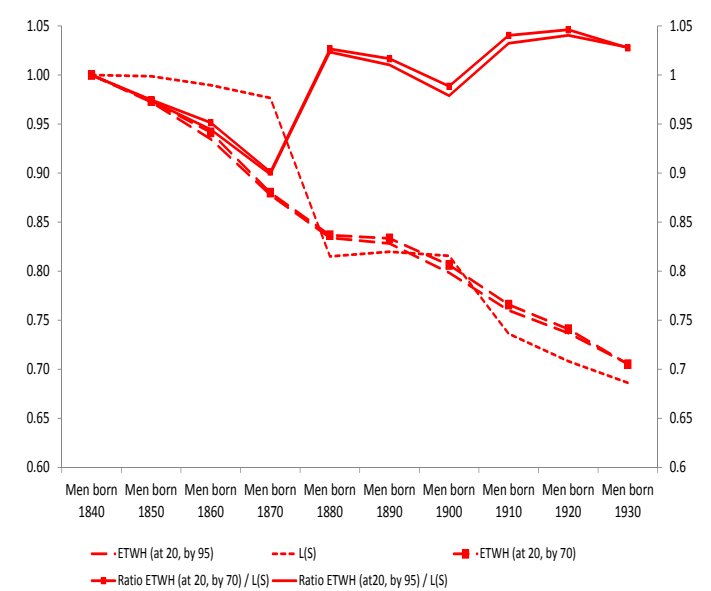

(b) Relative Changes, Normalized

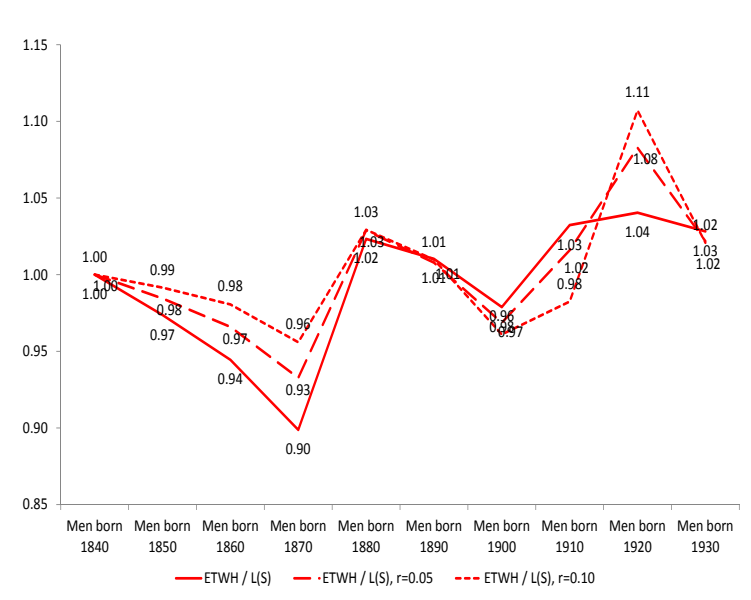

(d) Relative Changes With Discounting, Normalized

Panel (a) depicts $E T W H$ and $L_{S}$ for consecutive cohorts of men born between 1840 and 1930; estimates calculated at age 20 by age 70 and 95, respectively, assuming labor market entry at age 20. The data for ETWH are a replication of Figure 7 of Hazan (2009). Panel (b) presents the same data normalized to the level of the cohort born in 1840, as well as the ratios of $E T W H / L_{S}$ by age 70 and 95, respectively. Panel (c) depicts the ratio $E T W H / L_{S}$ by age 95 for $r=0$, $r=0.05$, and $r=0.10$. Panel (d) depicts the corresponding relative changes when normalized to the cohort born in 1840 .

Figure 4: Change in Benefits and Costs of Schooling, US 1840-1930 


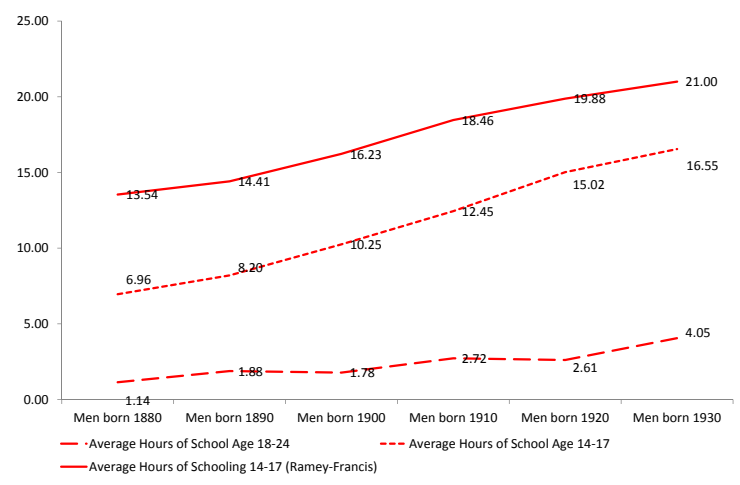

(a) School Hours, Absolute.

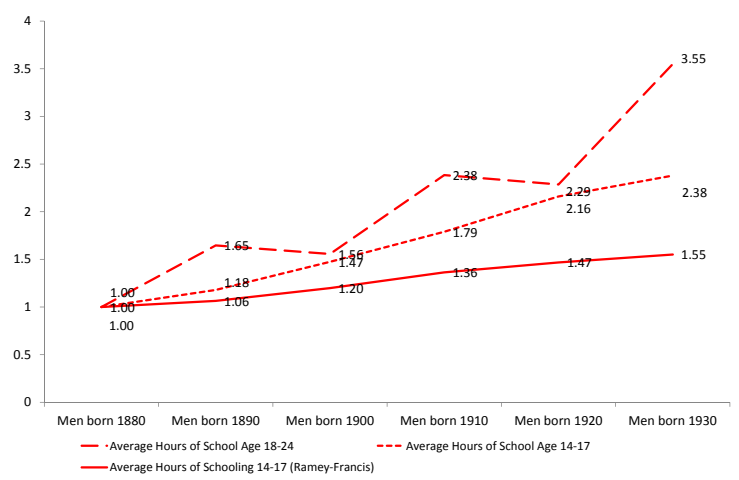

(b) School Hours, Relative.

Panel (a) depicts average hours in school for age groups 14-17 and 18-24 imputed for birth cohorts using the period data from Ramey and Francis (2009), excluding information on enrolment, as well as the original data by Ramey and Francis (2009). See also Figure 3A of Ramey and Francis (2009) and main text for details. Panel (b) depicts the same data normalized to the cohort of men born 1880 .

Figure 5: Evolution of Total Hours of Schooling, US 1840-1930
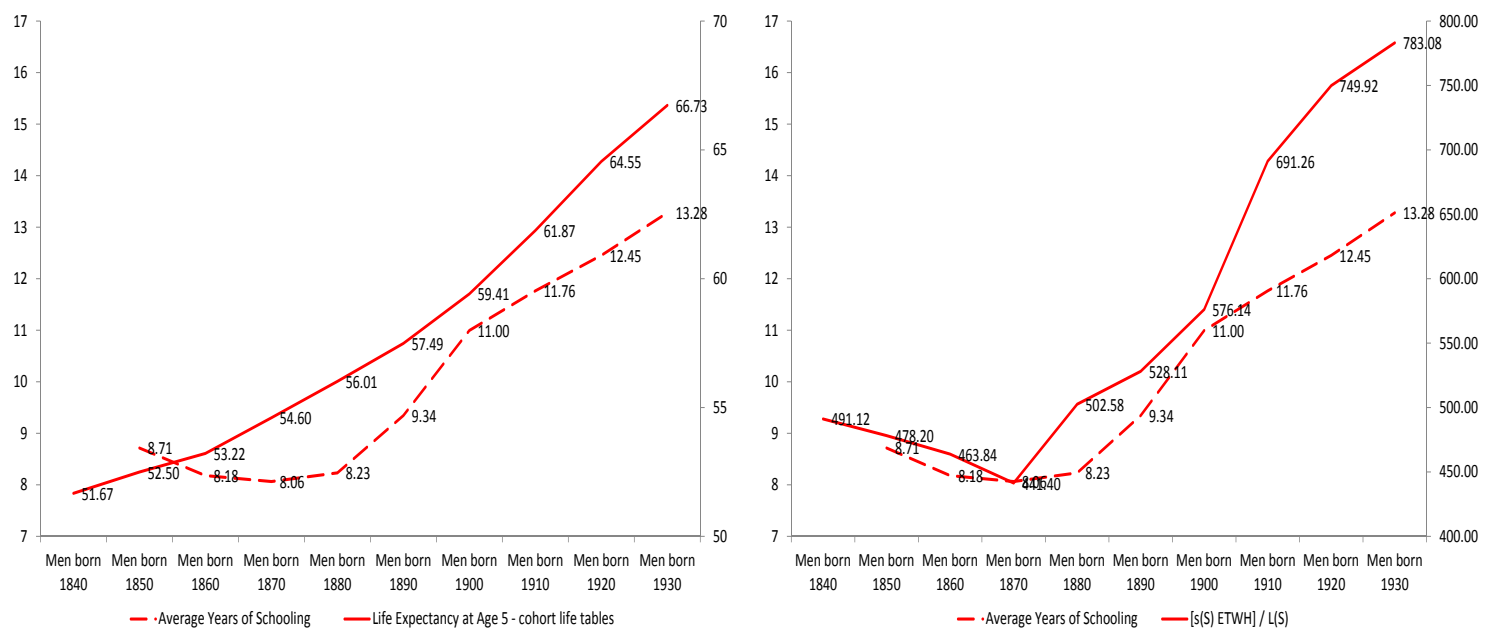

(a) Life Expectancy and Average Years of Schooling (b) Average Years of Schooling and Relative Benefits

Panel (a) is a replication of Figure 1 in Hazan (2009). Panel (b) depicts average years of schooling and the respective benefit-cost conditions, combining information on $E T W H / L_{S}$ from Figure 3 Panel (a) and school intensity at age 14-17 (Ramey-Francis) from Figure 5(a). See text for details.

Figure 6: Life Expectancy, Relative Benefits of Schooling and Average Years of Schooling, US $1840-1930$ 


\section{A Appendix: Analytical Derivations and Proofs}

\section{A.1 Costs and Benefits of Schooling: The Role of Simplifying Assumptions.}

This Appendix discusses the assumptions that need to be imposed on the model presented in Section 2 to obtain the same necessary conditions derived in Hazan (2006 and 2009). These further assumptions are:

- A1: $p_{t}=1$ for all $t \leq T$ and $p_{t}=0$ for all $t>T$;

- $A 2: \beta=b=1$;

- A3: The earnings function is exponential, $y(\bar{s}(S))=e^{\theta(\bar{s}(S))}$, with $\theta^{\prime}(\cdot)>0$ and $\theta^{\prime \prime}(\cdot) \leq 0$;

- A4: the optimal years of education $S$ can be chosen in continuous time

- A5: the production function of human capital is linear with unit slope, $g\left(s_{t}\right)=s_{t}$.

A1 implies a rectangular survival function: individuals survive with certainty until $\bar{T}$ and then die with certainty. Life expectancy coincides with longevity, $T=\bar{T}$ and reductions in mortality can affect schooling only by extending the maximum lifespan. According to $A 2$, the subjective discount factor is equal to the market discount factor, and that both equal one. From (5), A2 implies a flat labor supply $L_{t}=L$ for all $S<t \leq R$ and that the expected total work hours can be simply expressed as the product of labor hours and the time horizon dedicated to work, $E T W H=L \cdot(R-S)$. Finally, assumptions $A 3, A 4$ and $A 5$ jointly imply that the schooling choice at the extensive margin (how many years to spend in school) and at the intensive margin at $S$ (how much time to spend in school at $S$ ) collapse on each other 40

Jointly imposing all the assumptions $A 1-A 5$ one obtains a simplified expression of the expected benefits, (6),

$$
s_{S} \theta^{\prime}(\cdot) e^{\theta(\cdot)} \cdot L(R-S)
$$

and costs, (7),

$$
e^{\theta(\cdot)} \cdot L
$$

of schooling together with the prediction that

$$
s_{S}=L_{S}=L_{t}=1-l_{t}, t \geq S .
$$

Equalizing (13) and (14) and imposing the condition (15) one gets

$$
\frac{1}{\theta^{\prime}(\bar{s}(S))}=(R-S)(1-l)
$$

which is the first order condition for the optimal time spent at school derived in Hazan (2006) for $R=T$. Notice that $(1-l)$ in $(16)$ can be interpreted as labor hours $1-l=L$ only if (15) holds since, strictly speaking, this term represents the time devoted to school, $s_{S}$.

If one imposes $A 1-A 5$, considering endogenous or exogenous labor supply is irrelevant for the predictions. Further assuming that leisure at work and at study are exogenous and coincide,

- A6: $s=L=1$

implies that (for a non zero interest rate $r$ ) equation 16 can be written as,

$$
\frac{1}{\theta^{\prime}(\bar{s}(S))}=\frac{1-e^{-r(R-S)}}{r},
$$

\footnotetext{
${ }^{39}$ In continuous time, $A 2$ implies that the time preference rate and the discount rate are equal, $\rho=r=0$.

${ }^{40}$ Notice that the literature generally considers a production function of human capital which is strictly increasing and concave in time devoted to school, as well as a linear earnings function, see, e.g., Ben-Porath (1967) and Blinder and Weiss (1976). In contrast, Hazan (2009) considers a linear (identity) production function of human capital, $g(s(S))=s(S)$, and a concave earnings function and conjectures that this is a less restrictive assumption (see the discussion in footnote 10 on page 1834). As shown below this conjecture is not correct.
} 
which is the first order condition for the optimal time spent in school in Hazan (2009, p. 1834).

The magnitude $\theta^{\prime}(S)$ is a measure of the marginal change in earnings in response to an increase in schooling years $S$. Assuming that the earnings function $\theta(\cdot)$ is concave, so that $\theta^{\prime}(S)$ is a decreasing function of $S$, implies that the left hand side of (16) is increasing in $S$. Consequently, for a change in life expectancy to induce an increase in schooling $S$ in the optimum, it must be the case that also the right hand side of $(16)$ increases ${ }^{41}$ This observation lead to Proposition 1 in Hazan (2009, page 1835) that an increase in expected total work hours, ETWH, is a necessary condition for an increase in life expectancy to increase schooling. In the general formulation of the model, benefits (6) and costs (7) have three main components, however: the expected total working works hours (that depend on labor supply $L_{t}$ and survival rates $p_{t}$ ), the returns of the investment in schooling (that depend on $s_{S}$ and the production function of human capital, $g(\cdot)$ ), and the opportunity cost in terms of labor supply at school leaving age $L_{S}$.

This analysis shows that jointly imposing A1-A5 (respectively A1-A6) is sufficient to get the first order condition (16) (respectively (17). We next show that joinlty imposing these assumptions is also necessary. Consider the model presented in Section 2 and assume $A 1$ and A2. From (5), for any $S$, the optimal labor supply is flat, $L_{t}(S)=L(S)$ for all $S<t \leq R$ and $E T W H=L \cdot(R-S)$. Assuming, by contradiction, that condition 15 holds implies that the left hand sides of (4) and (5) are equal when evaluated at $t=S$ :

$$
g^{\prime}\left(s_{S}\right) y^{\prime}(\bar{s}(S)) L(S)(R-S)=y(\bar{s}(S)) .
$$

Following Hazan (2009), optimal years of schooling $S$ are determined by the equality of benefits and costs

$$
[y(\bar{s}(S))-y(\bar{s}(S-1))] L(S)(R-S)=L_{S}(S-1) y(\bar{s}(S-1)) .
$$

Combining (18) and (19), one gets,

$$
\frac{\frac{[y(\bar{s}(S))-y(\bar{s}(S-1))]}{y(\bar{s}(S-1))}}{\frac{g^{\prime}\left(s_{S}\right) y^{\prime}(\bar{s}(S))}{y(\bar{s}(S))}}=L_{s}(S-1) .
$$

The left hand side of (20) is the ratio between the (relative) increase in earnings obtained by staying at school the last period (that is the increase in earnings at the extensive margin of schooling), and at the (relative) increase in earnings obtained in the last hour spent at school (that is the increase in earnings at the intensive margin of schooling). Notice that even if one were to assume that $L_{s}(S-1)$ is proportional (or equal) to $s_{S}(S)$, condition (20) does not hold for a generic earnings function. In particular, the condition does not hold if one assumes a linear production function of human capital, A5. Imposing a rectangular survival probability distribution and restricting attention to a flat labor supply is therefore not sufficient to derive condition (15).

If schooling can be chosen in continuous time then, at the margin, $y(\bar{s}(S-1))$ converges to $y(\bar{s}(S))$, and $L(S-1)$ to $L(S)$. Further imposing $A 3$ and $A 4$ leads to

$$
\theta^{\prime}(\cdot) g(s(S)) e^{\theta(\cdot)}(R-S)=e^{\theta(\cdot)} L(S)
$$

and

$$
\theta^{\prime}(\cdot) g^{\prime}(s(S))(R-S)=e^{\theta(\cdot)} .
$$

Rewriting (20) using these conditions one gets

$$
\frac{g(s(S))}{g^{\prime}(s(S))}=L(S)
$$

and assuming again by contradiction (15) gives

$$
\frac{s(S) g^{\prime}(s(S))}{g(s(S))}=1
$$

\footnotetext{
${ }^{41}$ Notice that this prediction is the same irrespective of how the retirement age $R$ is set and, in particular, irrespective whether the retirement age is given exogenously or chosen endogenously.
} 
Notice, however, that condition (24) still does not hold in general. For example, the consideration of a general concave production function $g(\cdot)$, as is done in Ben-Porath (1967) and the subsequent literature, still leads to a contradiction.

Assuming A5 finally implies that 24) simplifies to,

$$
\frac{s(S)}{s(S)}=1
$$

which leads to no contradiction to the initial assumption 42

The analysis shows that the solution of the model in its general version presented in Section 2 does not imply the restriction $g\left(s_{S}\right)=s_{S}=L_{S}$ that, as documented in Section 3 is openly counterfactual. Also, the simplified first order conditions (16) (respectively (17)) can be obtained only when jointly imposing $A 1-A 5$ (respectively $A 1-A 6$ ).

\section{A.2 Rectangularization of the Survival Function}

Accounting for the compensation law (10), the unconditional probability of being alive at age $t$ with the Gompertz-Makeham function (9) can be written as

$$
p(t)=\exp \left\{-A t-\frac{B \bar{T}}{\ln \left(\frac{M}{B}\right)}\left(\exp \left[\ln \left(\frac{M}{B}\right) \frac{t}{\bar{T}}\right]-1\right)\right\} \geq 0,
$$

For any given intercept, $\ln M$, and lifespan, $\bar{T}$, the effect of a (compensated) change in $B$ on the unconditional survival probability at age $t$ is given by

$$
\frac{\partial p(t)}{\partial B}=-p(t) \frac{\bar{T} f(M, B, t, \bar{T})}{\ln \left(\frac{M}{B}\right)}\left[1-\frac{t}{\bar{T}}+\frac{1}{\ln \left(\frac{M}{B}\right)}-\frac{t}{\bar{T}} \frac{1}{f(M, B, t, \bar{T})}\right]
$$

where

$$
f(M, B, t, \bar{T})=\exp \left[\ln \left(\frac{M}{B}\right) \frac{t}{\bar{T}}\right]-1
$$

Notice that $M>B$ from the compensation law 110 , while $1>t / \bar{T}$ by definition of $\bar{T}$. This implies that the sign of the term before square brackets in $(27)$ is negative for all $t \in(0, \bar{T})$. To see that the term in square brackets of $(27)$ is positive for all $t \in(0, \bar{T})$ it is sufficient to notice that

$$
\frac{1}{\ln (M / B)}>\frac{t / \bar{T}}{f(M, B, t, \bar{T})} .
$$

From (10) we have $\ln (M / B)=\delta \bar{T}$ and $f(M, B, t, \bar{T})=\exp (\delta t)-1$. Condition 29$)$ can therefore be rewritten as $\exp (\delta t)>1+\delta t$ which is always true for all $t>0$. Hence, $\partial p(t) / \partial B<0$ for all $t \in(0, \bar{T})$ which implies that a reduction in $B$ (that is a reduction in baseline mortality) increases survival probabilities at these ages.

Finally, the existence of the compensation law implies: $\lim _{t \rightarrow 0} \partial p(t) / \partial B=\lim _{t \rightarrow \bar{T}} \partial p(t) / \partial B=$ 0 . Since $\lim _{t \rightarrow 0} f(M, B, t, \bar{T})=1 / \ln (M / B)$ while $\lim _{t \rightarrow \bar{T}} f(M, B, t, \bar{T})=B /(M-B)$ we have

$$
\lim _{t \rightarrow 0} \frac{\partial p(t)}{\partial B}=-1 \cdot \frac{\bar{T}}{\ln (M / B)} \cdot 0 \cdot[1]=0 .
$$

and

$$
\lim _{t \rightarrow \bar{T}} \frac{\partial p(t)}{\partial B}=-0 \cdot \frac{\bar{T}}{\ln (M / B)} \cdot\left(\frac{M}{B}-1\right) \cdot\left[\frac{1}{\ln (M / B)}-\frac{B}{M-B}\right]=0,
$$

since $p(0)=1$ and, by definition of $\bar{T}, p(\bar{T})=0$.

\footnotetext{
${ }^{42}$ Assuming a general iso-elastic functional form $g(s(S))=s(S)^{\beta}$ with $\beta<1$ is not enough since condition 23. and $L(S)=s(S)$ jointly imply

which is not possible unless $\beta=1$.

$$
\frac{s(S)}{\beta}=L(S)=s(S)
$$
}




\section{B Online Appendix: Additional Figures and Tables}

- Figure 7, Benefits and Costs of Schooling: Alternative Estimates;

- Figure 8: Benefits and Costs of Schooling: Alternative Estimates with Different Discount Rates;

- Figure 9. Benefits and Costs of Schooling: Alternative Estimates Calculated at Age 10;

- Table 1; Coefficient Estimates of the Gompertz-Makeham Law of Mortality. 


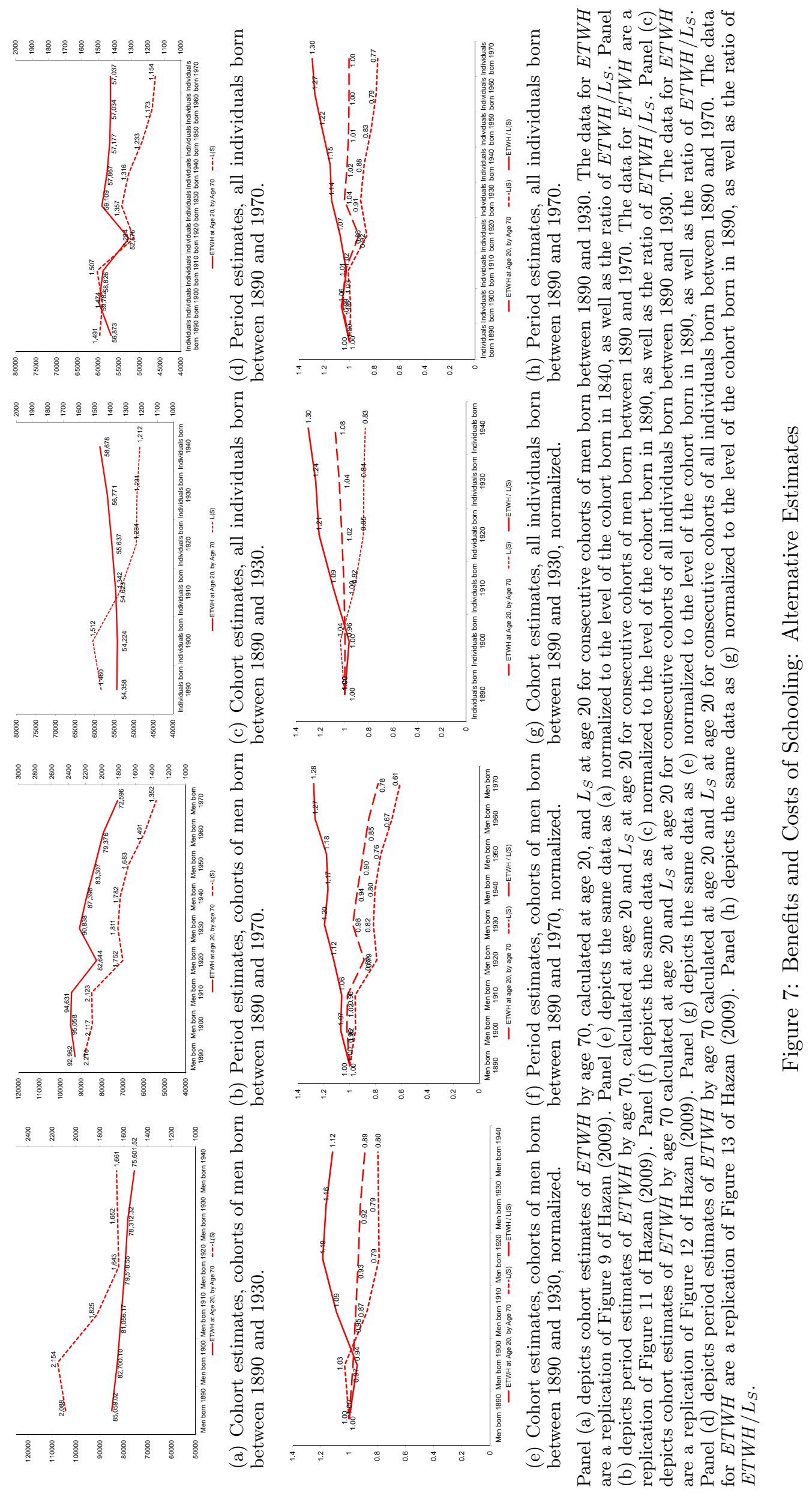



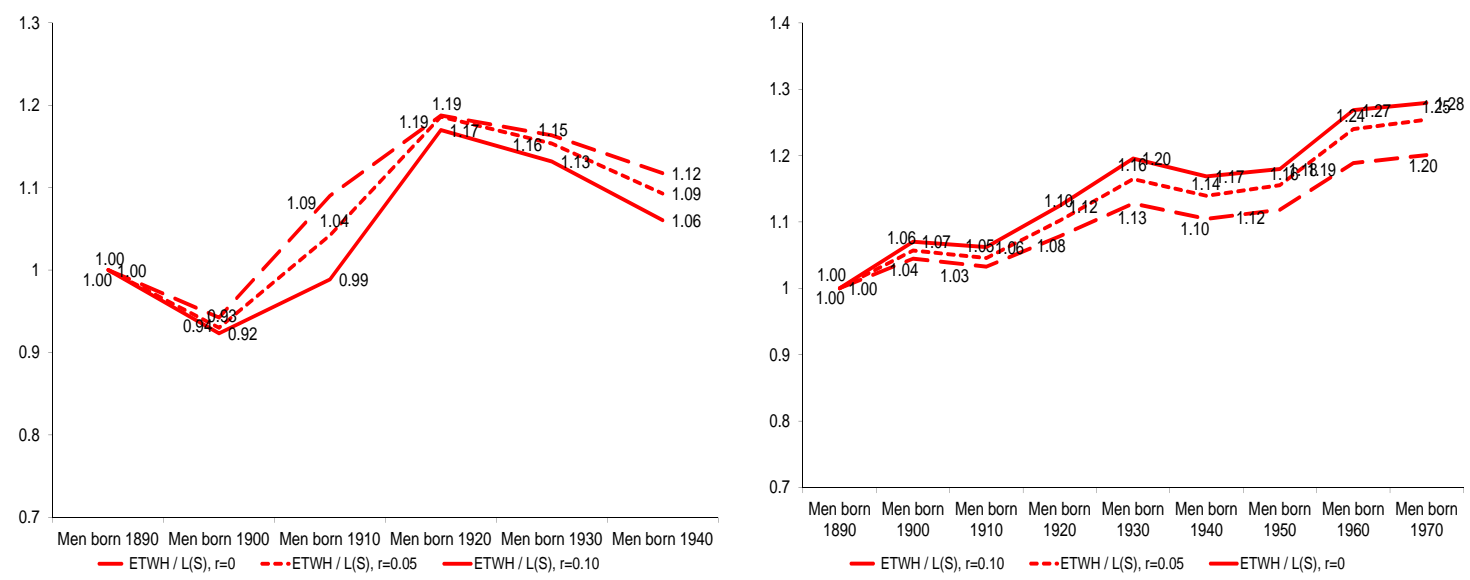

(a) Relative Changes and Discounting: Men Cohort (b) Relative Changes and Discounting: Men Period Data

Data
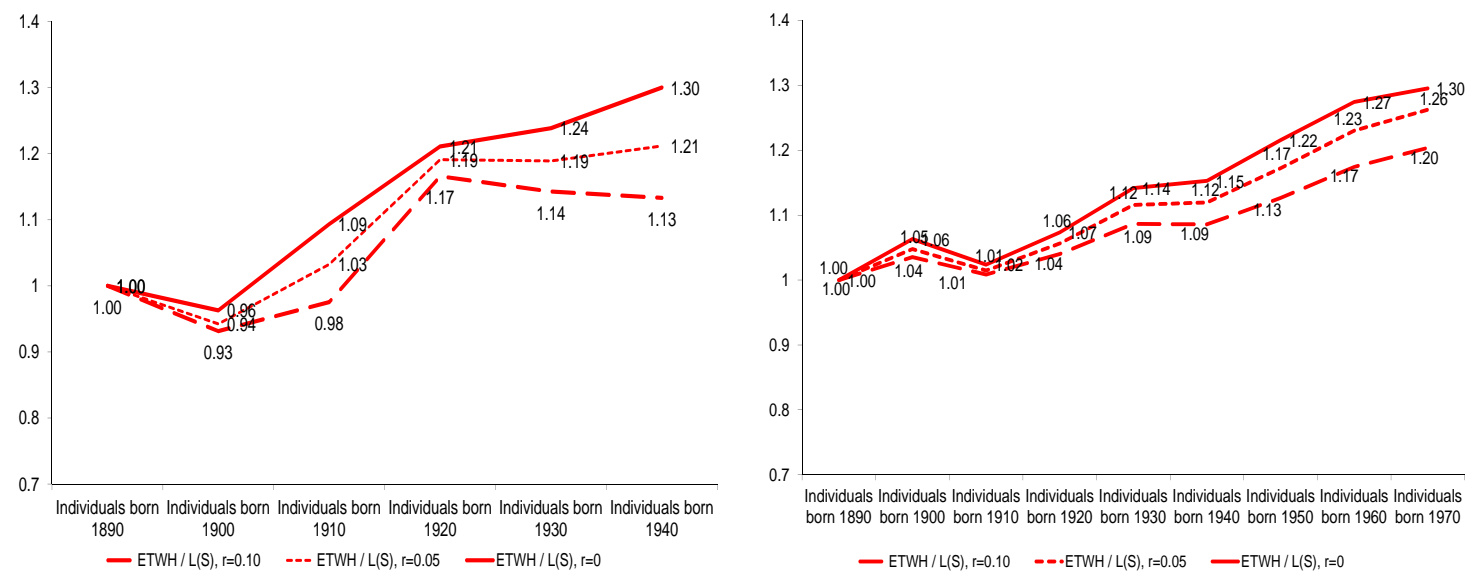

(c) Relative Changes and Discounting: All Individu- (d) Relative Changes and Discounting: All Individuals Cohort Data als Period Data

This figure displays relative benefits in terms of the ratio $E T W H / L_{S}$, normalized to the value for the first observed cohort. The data correspond to the data shown in Figure 7

Figure 8: Benefits and Costs of Schooling: Alternative Estimates with Different Discount Rates 


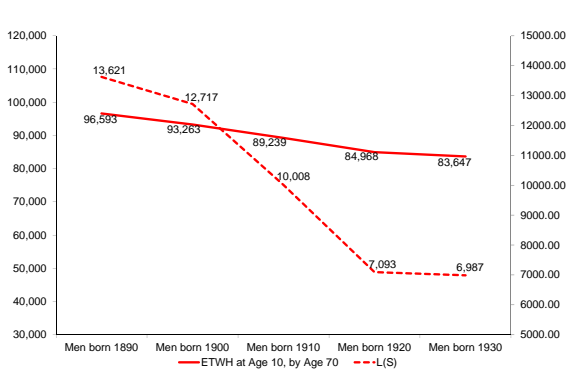

(a) Cohort estimates, cohorts of men born between 1890 and 1930 .

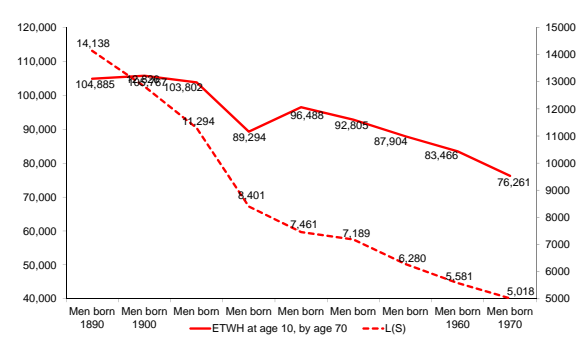

(c) Period estimates, cohorts of men born between 1890 and 1970 .

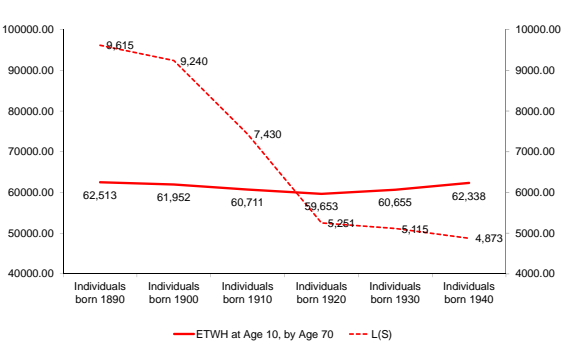

(e) Cohort estimates, all individuals born between 1890 and 1930 .

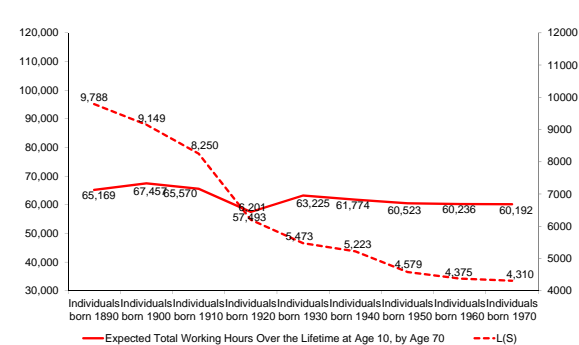

(g) Period estimates, all individuals born between 1890 and 1970 .

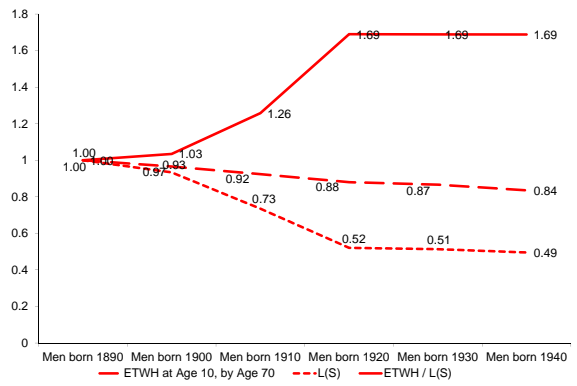

(b) Cohort estimates, cohorts of men born between 1890 and 1930, normalized.

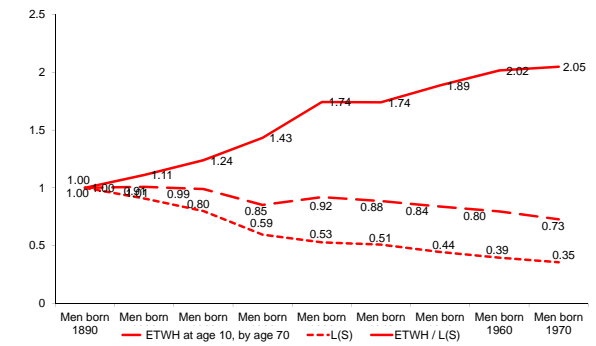

(d) Period estimates, cohorts of men born between 1890 and 1970, normalized.

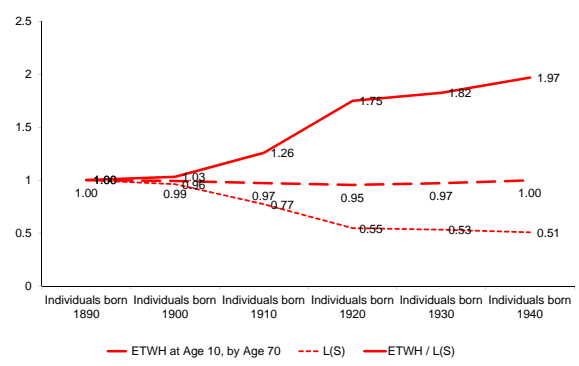

(f) Cohort estimates, all individuals born between 1890 and 1930, normalized.

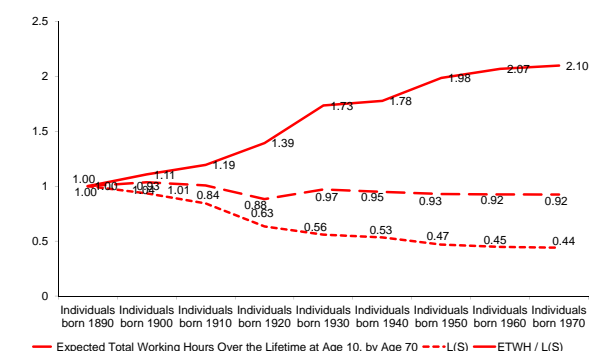

(h) Period estimates, all individuals born between 1890 and 1970 .

Panel (a) depicts cohort estimates of $E T W H$ by age 70, calculated at age 10 , and $L_{S}$ between age 10 and 20 for consecutive cohorts of men born between 1890 and 1930. The data for ETWH are a replication of Figure 9 of Hazan (2009). Panel (b) depicts the same data as (a) normalized to the level of the cohort born in 1840, as well as the ratio of $E T W H / L_{S}$. Panel (c) depicts period estimates of $E T W H$ by age 70 , calculated at age 10 and $L_{S}$ between age 10 and 20 for consecutive cohorts of men born between 1890 and 1970. The data for ETWH are a replication of Figure 11 of Hazan (2009). Panel (d) depicts the same data as (c) normalized to the level of the cohort born in 1890, as well as the ratio of $E T W H / L_{S}$. Panel (e) depicts cohort estimates of $E T W H$ by age 70 calculated at age 10 and $L_{S}$ between age 10 and 20 for consecutive cohorts of all individuals born between 1890 and 1930. The data for ETWH are a replication of Figure 12 of Hazan (2009). Panel (f) depicts the same data as (e) normalized to the level of the cohort born in 1890, as well as the ratio of $E T W H / L_{S}$. Panel (g) depicts period estimates of $E T W H$ by age 70 calculated at age 10 and $L_{S}$ between age 10 and 20 for consecutive cohorts of all individuals born between 1890 and 1970. The data for ETWH are a replication of Figure 13 of Hazan (2009). Panel (h) depicts the same data as (g) normalized to the level of the cohort born in 1890, as well as the ratio of $E T W H / L_{S}$.

Figure 9: Benefits and Costs of Schooling: Alternative Estimates Calculated at Age 10 


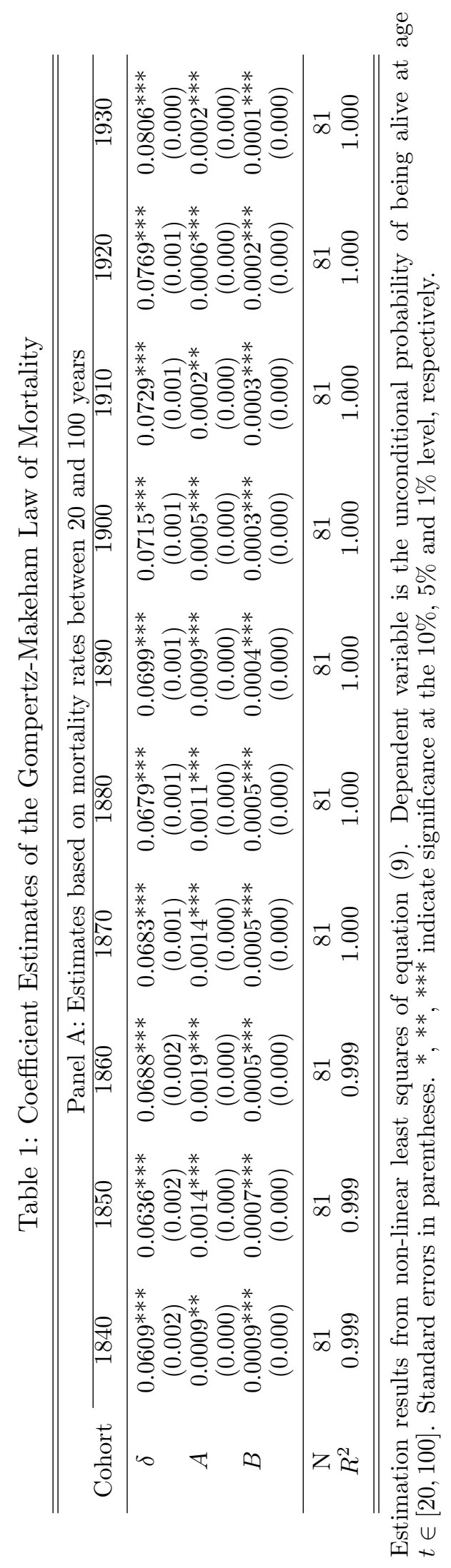

